\title{
Therapy of Type 2 Diabetes
}

Authors

Rüdiger Landgraf1, Jens Aberle², Andreas L. Birkenfeld33, 4, Baptist Gallwitz' ${ }^{4}$, Monika Kellerer ${ }^{5}$, Harald Klein ${ }^{6}$, Dirk Müller-Wieland7 ${ }^{7}$, Michael A. Nauck ${ }^{8}$, Hans-Martin Reuter ${ }^{9}$, Erhard Siegel ${ }^{10}$

\section{Affiliations}

1 German Diabetes Foundationg, Munich, Germany

2 Section Endocrinology and Diabetology, University Obesity Centre Hamburg, University Hospital HamburgEppendorf, Germany

3 University Hospital Carl Gustav Carus at the TU Dresden, Department of Metabolic Vascular Medicine, Dresden and German Center for Diabetes Research (DZD e. V.), Neuherberg, Germany

4 Medical Clinic IV, University Hospital Tübingen, Germany

5 Centre for Internal Medicine I, Marienhospital, Stuttgart, Germany

6 Medical Clinic I, Berufsgenossenschaftliches University Hospital Bergmannsheil, Bochum, Germany

7 Medical Clinic I, University Hospital, Aachen, Germany

8 Diabetes Center Bochum-Hattingen, St.-Josef-Hospital, Ruhr-University, Bochum, Germany

9 Diabetological Practice, Jena, Germany

10 Department of Internal Medicine - Gastroenterology, Diabetology/Endocrinology and Nutritional Medicine, St. Josefkrankenhaus Heidelberg $\mathrm{GmbH}$, Heidelberg, Germany

\section{Bibliography}

DOI https://doi.org/10.1055/a-1018-9106

Exp Clin Endocrinol Diabetes 2019; 127 (Suppl 1): S73-S92

(c) J. A. Barth Verlag in Georg Thieme Verlag KG Stuttgart .

New York

ISSN 0947-7349

Correspondence

Prof. Dr. med. Rüdiger Landgraf

German Diabetes Foundation

Germeringer Straße 101/2

82131 Gauting

Germany

ruediger.landgraf@gmx.de
The practical recommendations of the German Diabetes Society/ Deutsche Diabetes Gesellschaft (DDG) together with the German Society for Internal Medicine/Deutschen Gesellschaft für Innere Medizin (DGIM) are based on the contents of the National Treatment Guideline (Nationale Versorgungsleitlinie NVL) "Therapy of Type 2 Diabetes" [1]. The modifications in therapy and their justifications made in the present DDG practical recommendations were updated on the basis of new randomized controlled trials (RCTs) and meta-analyses and were consented by the DDG and the DGIM.

\section{Definition of Type 2 Diabetes}

Type 2 diabetes is a chronic, very heterogeneous, multi-factorial, progressive disease characterized by inherited and acquired insulin resistance and qualitative and quantitative insulin secretion disturbances.
Influenceable and uninfluenceable risk factors for type 2 diabetes are listed in the "Risk factors for type 2 diabetes" infobox.

\section{Therapeutic goals}

In the present recommendations, target ranges are identified which - with varying levels of strengths of evidence - inform the physician and the patient on which target range/target value should be aimed for according to current medical knowledge based on evidence and consensus. The main objective remains to set individual therapy goals primarily together with the patient and possibly his or her relatives and agreeing them optimally in writing on a quarterly basis (e. g. in the Health Passport Diabetes).

\section{General and specific therapeutic goals}

The therapeutic goals of people with type 2 diabetes depend on patient preference, comorbidity, duration of the disease, age and life expectancy, quality of life, cultural conditions, psychosocial circumstances and possibilities as well as abilities of the persons 


\section{RISK FACTORS FOR CARDIOVASCULAR DISEASES AND TYPE 2 DIABETES}

\section{Uninfluenceable}

- Higher age

- Sex

- Ethnicity

- Positive family history

- Gestational diabetes (in the history)

- Intrauterine development (foetal programming)

\section{Influenceable}

- Visceral obesity

- Fatty liver

- Depression

- Poor sleep (obstructive sleep apnoea, OSA)

- Physical inactivity

- High-energy, low-fibre food

- High sugar consumption (soft drinks etc.)

- Excessive alcohol consumption (fatty liver)

- Smoking

- Diabetogenic drugs

- Diabetogenic environment (e.g. deprivation) = disadvantage due to lack of resources, excessive chronic noise and air pollution)

\section{Metabolic syndrome [2]}

at least 3 out of 5 criteria must be fulfilled:

- Abdominal obesity (waist circumference): men * $>94$ cm; women $^{* *}>80 \mathrm{~cm}$

- Triglycerides: $\geq 150 \mathrm{mg} / \mathrm{dl}$ or $\geq 1.7 \mathrm{mmol} / \mathrm{l}$

- HDL cholesterol ${ }^{* * *}$ : Men $<40 \mathrm{mg} / \mathrm{dl}$ or $<1.03 \mathrm{mmol} / \mathrm{l}$; women: $<50 \mathrm{mg} / \mathrm{dl}$ or $<1.29 \mathrm{mmol} / \mathrm{l}$

- Elevated blood pressure: $\geq 130 / \geq 85 \mathrm{mmHg}$

- Fasting plasma glucose ${ }^{* * *}: \geq 100 \mathrm{mg} / \mathrm{dl}$ or $\geq 5 \mathrm{mmol} / \mathrm{l}$ or pre-existing diabetes

* I** People from: Southeast Asia or China: $90 / 80 \mathrm{~cm}$;

Japan: $85 / 90 \mathrm{~cm}$

*** Pharmacological intervention is an alternative criterion

concerned. The diagnosis of type 2 diabetes, which is often experienced by those affected as a severe life restriction, requires a strategy of consent and gradual intensification of therapy (exception: severe metabolic decompensation). In people with type 2 diabetes, individualized therapy goals should be agreed for the following vascular risk parameters (infobox "General treatment and care goals"; $>$ Table 1):

- Lifestyle

- Blood pressure

- Glucose metabolism

- Lipid status

- Body weight

\section{GENERAL TREATMENT AND CARE GOALS}

- Preservation or restoration of quality of life

- Empowerment of those affected in dealing with the disease and its complications

- Reduction of stigma associated with the disease

- Treatment satisfaction

- Promotion of therapy adherence

- Reduction of risk for cardiac, cerebrovascular and other macrovascular complications

- Avoidance and treatment of microvascular and neurological complications

- Avoidance and treatment of diabetic foot syndrome

- Treatment and improvement of comorbidity

- Minimization of side effects of therapy (e. g. severe hypoglycaemia, weight gain)

- Reduction of the burden of complex therapies (polypharmacy, drug interactions)

- Reduction of morbidity

- Normalisation of shortened life expectancy with good quality of life

$\checkmark$ Table 1 Orientation parameters for therapeutical goals.

\begin{tabular}{|c|c|c|}
\hline \multirow[t]{2}{*}{ Indicator } & \multicolumn{2}{|c|}{ Orientation for therapeutic goals } \\
\hline & $\mathrm{mg} / \mathrm{dl}$ & $\mathrm{mmol} / \mathrm{l}$ \\
\hline $\begin{array}{l}\text { Fasting/ } \\
\text { preprandial } \\
\text { plasma glucose } \\
\text { (venous) }\end{array}$ & $100-125$ & $5.6-6.9$ \\
\hline $\begin{array}{l}\text { Postprandial } \\
\text { plasma glucose } \\
\text { (venous) } 1-2 \mathrm{~h}\end{array}$ & $140-199$ & $7.8-11.0$ \\
\hline postprandial & \multicolumn{2}{|c|}{ Individualization of the therapeutic goals } \\
\hline HbA1c & \multicolumn{2}{|c|}{$\begin{array}{l}\mathrm{HbA} 1 \mathrm{c} \text { target range of } 6.5-7.5 \% \text { ( } 48-58 \mathrm{mmol} / \\
\text { mol } \mathrm{Hb} \text { ) to prevent complications and severe } \\
\text { hypoglycaemia. } \\
\text { In elderly people with multimorbidity and } \\
\text { people with severely reduced life expectancy } \\
\mathrm{HbA} 1 \mathrm{c}<8.0 \%(<64 \mathrm{mmol} / \mathrm{mol} \mathrm{Hb}) \text {, } \\
\text { sometimes }<8.5 \%(<69 \mathrm{mmol} / \mathrm{mol} \mathrm{Hb}) \text {. If only } \\
\text { antidiabetic medications without intrinsic } \\
\text { hypoglycaemia risk are used, lower } \mathrm{HbA} 1 \mathrm{c} \\
\text { targets may also be defined. }\end{array}$} \\
\hline Uric acid & \multicolumn{2}{|c|}{ Serum levels $\leq 6.0 \mathrm{mg} / \mathrm{dl}(357 \mu \mathrm{mol} / \mathrm{l})[7]$} \\
\hline Lipids & \multicolumn{2}{|c|}{$\begin{array}{l}\text { LDL cholesterol reduction to target values } \\
<100 \mathrm{mg} / \mathrm{dl}(<2.6 \mathrm{mmol} / \mathrm{l}) ; \text { for } \mathrm{CHD} \text { or other } \\
\text { risk factors }<70 \mathrm{mg} / \mathrm{dl}(<1.8 \mathrm{mmol} / \mathrm{l}) \text { and at } \\
\text { least a } 50 \% \text { reduction }[8] .\end{array}$} \\
\hline $\begin{array}{l}\text { Weight loss for } \\
\text { excess weight }\end{array}$ & \multicolumn{2}{|c|}{$\begin{array}{l}\text { For BMI from } 27-35 \mathrm{~kg} / \mathrm{m}^{2}:>5 \% \text { weight } \\
\text { reduction; for BMI }>35 \mathrm{~kg} / \mathrm{m}^{2}:>10 \% \text { weight } \\
\text { reduction }\end{array}$} \\
\hline Blood pressure & \multicolumn{2}{|c|}{$\begin{array}{l}\text { Systolic blood pressure: } 120-140 \mathrm{mmHg}(\geq 65 \\
\text { years } 130-139 \mathrm{mmHg} ; \leq 65 \text { years } 120- \\
129 \mathrm{mmH} \text { ); diastolic blood pres- } \\
\text { sure: }<80 \mathrm{mmHg} \text { (not }<70 \mathrm{mmHg}) \text {; if the } \\
\text { therapy has no relevant side effects [9] }\end{array}$} \\
\hline
\end{tabular}




\section{Diagnosis}

Medical history and clinical examinations are listed in $>$ Table 2 and monitoring of people with type 2 diabetes are depicted in - Table 3.

Diagnosis is ensured by standardized and quality-assured laboratory tests for both plasma glucose and HbA1c. Devices for selfmeasurement (POCT systems) must successfully pass external quality assurance otherwise they are unsuitable for the diagnosis. Since a large number of preanalytical, analytical and interpretational problems are present in the diagnosis of diabetes, the updated and detailed practical recommendations for diabetes diagnosis should be referred to in addition to other sources of information [3-5].

\section{Therapy}

\section{Non-pharmacological therapy}

\section{Education and training}

A structured, evaluated, target group-specific and topic-specific training and treatment programme should be offered to all patients with diabetes and, where appropriate, their relatives as an indispensable component of the treatment [6].

\section{Plasma glucose self-monitoring}

In the case of an indication for plasma glucose self-monitoring, the situations listed in > Table 4 should be taken into account in people with type 2 diabetes. The glucose self-monitoring should result in eventually necessary therapeutic adjustments.

Urine glucose analyses are not standard in the diagnosis, therapy decision making and monitoring, because urine glucose becomes only positive in the case of high blood glucose values (renal glucose transport capacity is very different intra- and interindividually, it is age-dependent, it is not systematically examined at reduced kidney function, it lowers with certain diseases and is not useful in pregnancy or with the use of drugs such as SGLT-2 inhibitors).

\section{Nutritional therapy and consultation}

Nutritional recommendations for people with type 2 diabetes should include the following key points. These are just a few recommendations:

- Motivation for healthy, well-balanced diet considering the patient's previous nutrition routine.

- As far as possible, the use of industrial food processing equipment should be avoided, and the intake of sucrose should be limited (WHO recommendation $<25 \mathrm{~g} /$ day).

- The estimation of type and amount of carbohydrates of each meal should be used as an essential metabolic control strategy for people with type 2 diabetes who inject insulin.

- People with type 2 diabetes without insulin therapy should be able to recognize foods which increase blood glucose.

- For people with type 2 diabetes and renal insufficiency, a daily protein intake of $0,8 \mathrm{~g} / \mathrm{kg}$ is recommended. In endstage renal disease, the protein intake should be increased to $1.2-1.3 \mathrm{~g} / \mathrm{kg}$.

- People with type 2 diabetes should be should be advised how to deal with alcohol in a differentiated manner as part of the individual consultation.
- Practical recommendations for a healthy and balanced diet, a Mediterranean diet at best [10-13].

- No complete ban of sugar, but the avoidance of large quantities of glucose, fructose, sucrose and sugar alcohols (e. g. sorbitol, xylitol) or beverages containing these substances.

- Avoidance of large portions and frequent consumption of fatty foods, e. g. fatty meat, fatty sausages, fatty cheese, fatty baked goods, fatty ready-made products, fatty fast food, cream, chocolate, chips etc.

- Table 2 Medical history and clinical examinations in people with type 2 diabetes.

\begin{tabular}{|c|c|}
\hline History and examination & \\
\hline $\begin{array}{l}\text { History } \\
\text { It should be noted that type } 2 \\
\text { diabetes is frequently poor in } \\
\text { symptoms or asymptomatic and } \\
\text { that the symptoms are often } \\
\text { overlooked. }\end{array}$ & $\begin{array}{l}\text { - Overweight/obesity } \\
\text { - High blood pressure } \\
\text { - Dyslipidemia } \\
\text { - Thirst } \\
\text { - Frequent urination } \\
\text { - Involuntary weight loss } \\
\text { - Tendency to infection } \\
\text { - especially infections of the } \\
\text { - skin or mucous membranes } \\
\text { - Exhaustion, fatigue, weakness } \\
\text { - Physical activity } \\
\text { - Drug intake (e. g. glucocorti- } \\
\text { - } \text { Alcoids, psychotherapeutics) } \\
\text { - Smoking consumption } \\
\text { - Depression } \\
\text { - Exertional dyspnea } \\
\text { - NYHA Class } \\
\text { - Angina symptoms } \\
\text { - Intermittent claudication } \\
\text { - (walking distance) } \\
\text { - Memory deficits, cognitive } \\
\text { - } \text { Vysfunction } \\
\text { - Erectile dysfunction } \\
\text { - Birth of children> } 4000 \mathrm{~g}\end{array}$ \\
\hline Family history & $\begin{array}{l}\text { - Diabetes } \\
\text { - Overweight } \\
\text { - High blood pressure } \\
\text { - Dyslipidemia } \\
\text { - Retinopathy } \\
\text { - Myocardial infarction } \\
\text { - Stroke } \\
\text { - Kidney disease } \\
\text { - Amputation }\end{array}$ \\
\hline Physical examination & $\begin{array}{l}\text { - Height } \\
\text { - Weight (BMI) } \\
\text { - Waist circumference (in the } \\
\text { middle between lower rib-bone } \\
\text { and upper iliac crest right after } \\
\text { exhaling normally) } \\
\text { - Cardiovascular system } \\
\text { - Blood pressure } \\
\text { - Peripheral arteries, pulse status } \\
\text { - Peripheral nervous system [18] } \\
\text { - Skin } \\
\text { - Eye examinations [19] } \\
\text { - Foot examinations [20] }\end{array}$ \\
\hline
\end{tabular}




\begin{tabular}{|l|l|}
\hline History and examination & \\
\hline Laboratory values & - Plasma glucose \\
Optional GAD: antibodies test for & - Blood count \\
the sometimes difficult differentia- & - HbA1c \\
tion to type 1 diabetes or LADA & - Creatinine \\
and insulin or better C-peptide & - eGFR \\
(with HOMA2-B and HOMA2-IR) in & - Potassium \\
cases of unclear differential & - Lipid profile \\
diagnosis or for subtyping of type & - Gamma GT \\
2 diabetes if a therapeutic & - AST \\
consequence results (see also the & - ALT [21] \\
practical recommendation & - Uric acid [7] \\
"Definition, classification and & - Urine analysis including \\
diagnosis of diabetes mellitus' in & determination of quantitative \\
this supplement) & albuminuria [22], ketones in \\
& urine or blood (only for high \\
& glucose values; for SGLT-2 \\
& inhibitor therapy, also at plasma \\
& glucose values <250 mg/dl \\
& [13.9 mmol/I]) \\
\hline Technical examinations & - Resting and exercise ECG \\
& [23-24] \\
& - Echocardiography with or \\
& without pharmacological stress \\
& as an alternative to a stress ECG; \\
& ask about HFpEF/HFrEF \\
& - Abdominal sonography (fatty \\
& liver and others) \\
& - Eye examination \\
- Ankle brachial index for weak or \\
not palpapabler pulses in the \\
feet (consider: media sclerosis) \\
\hline
\end{tabular}

- Choose vegetable fats, e. g. oils, nuts, seeds.

- Enrich your meals with dietary fibres, e.g. vegetables, fresh fruit, whole grain cereals.

Weight reduction in overweight and obese people with type 2 diabetes supports the reduction of vascular risks, increases self-esteem, quality of life and can lead to remission in the early stages of type 2 diabetes [13-15]. See also [16]: S3 guideline Prevention and treatment of obesity/Prävention und Therapie der Adipositas“ (www.awmf.org/leitlinien/detail/ll/050-001.html).

Physical activity ( $\triangleright$ Fig. 1)

- People with type 2 diabetes should be motivated to increase their physical activity.

- It should be decided which types of exercise or sports are suitable for people with type 2 diabetes on an individual basis.

- Aerobic endurance training and strength training to build and maintain musculature should be offered as structured movement programmes.

- At least 150 min of moderate intensity exercise are recommended per week [25].

- In particular, it is recommended for people with type 2 diabetes in the second half of their life to train dexterity, reactions, coordination, flexibility and mobility.
- Table 3 Monitoring of people with type 2 diabetes.

\begin{tabular}{|c|c|}
\hline $\begin{array}{l}\text { History/Investiga- } \\
\text { tion/Screening }\end{array}$ & \\
\hline History & $\begin{array}{l}\text { - Diabetes duration } \\
\text { - Weight/BMI, waist-height ratio if } \\
\text { applicable (weight progression, excess } \\
\text { - } \text { Beight) } \\
\text { - } \text { Blood pressure } \\
\text { - Poot status } \\
\text { - Previous therapy (complete medication } \\
\text { - Plan if possible) } \\
\text { - Physical activity } \\
\text { - Eating habits } \\
\text { - Smoking } \\
\text { - Diabetes education and training } \\
\text { programme carried out, blood glucose } \\
\text { - } \text { self-monitoring } \\
\text { - } \text { severity) } \\
\text { - Dnxiety } \\
\text { - Eepression }\end{array}$ \\
\hline Physical examination & $\begin{array}{l}\text { - Weight } \\
\text { - Blood pressure } \\
\text { - Cardiovascular system } \\
\text { - Lungs } \\
\text { - Examination of injection sites in } \\
\text { patients treated with insulin and/or } \\
\text { GLP-1-RA } \\
\text { - Examination of the FGM/CGM puncture } \\
\text { or implant sites }\end{array}$ \\
\hline Laboratory values & $\begin{array}{l}\text { - HbA1c } \\
\text { - Creatinine clearance rate (eGFR) } \\
\text { - Lipid profile } \\
\text { - Urine analyses incl. albuminuria [22], } \\
\text { ketones in urine or blood (only for high } \\
\text { blood glucose levels; if applicable with } \\
\text { SGLT-2 inhibitor therapy) }\end{array}$ \\
\hline $\begin{array}{l}\text { Screening for diabetic } \\
\text { neuropathy [18] }\end{array}$ & $\begin{array}{l}\text { People with type } 2 \text { diabetes neuropathy } \\
\text { should be screened once per year from the } \\
\text { moment of diagnosis for sensorimotor and } \\
\text { autonomic neuropathy. }\end{array}$ \\
\hline $\begin{array}{l}\text { Screening for foot } \\
\text { lesions [20] }\end{array}$ & $\begin{array}{l}\text { People with type } 2 \text { diabetes also with no } \\
\text { clinical findings of sensorimotor } \\
\text { neuropathy should be examined for foot } \\
\text { lesions at least once a year. If there are } \\
\text { already clinical findings of sensorimotor } \\
\text { neuropathy, regular examinations for foot } \\
\text { lesions should be carried out every } 3-6 \\
\text { months. }\end{array}$ \\
\hline $\begin{array}{l}\text { Screening for } \\
\text { nephropathy [22] }\end{array}$ & $\begin{array}{l}\text { People with type } 2 \text { diabetes should be } \\
\text { examined for albuminuria at least once a } \\
\text { year, as this allows a significant additional } \\
\text { risk assessment for cardiovascular and } \\
\text { renal complications. In addition, the eGFR } \\
\text { should be determined, whereby the } \\
\text { frequency of the measurement varies } \\
\text { depending on the stage of renal disease } \\
\text { and possible renal complications } \\
\text { (nephrotoxic substances, contrast agents, } \\
\text { hypovolemia). }\end{array}$ \\
\hline
\end{tabular}


- Table 3 Continued

\begin{tabular}{|c|c|}
\hline $\begin{array}{l}\text { History/Investiga- } \\
\text { tion/Screening }\end{array}$ & \\
\hline $\begin{array}{l}\text { Screening for retinal } \\
\text { complications [19] }\end{array}$ & $\begin{array}{l}\text { An ophthalmic screening should be } \\
\text { performed: } \\
\text { - for type } 2 \text { diabetes upon diagnosis } \\
\text { (initial examination). If no diabetic } \\
\text { retinal change is detected, the } \\
\text { screening interval should be } \\
\text { - in case of known low risk } \\
\text { (=no ophthalmological risk and no } \\
\text { general risk) } 2 \text { years, } \\
\text { - for all other risk constellations } 1 \text { year. } \\
\text { If the ophthalmologist does not know } \\
\text { the general risk factors, he should treat } \\
\text { the patient as if he had an unfavourable } \\
\text { general risk profile. } \\
\text { Patients with diabetic retinopathy } \\
\text { changes (=ophthalmic risk) should be } \\
\text { examined annually or more frequently, } \\
\text { depending on the findings. } \\
\text { In the case of newly occurring } \\
\text { symptoms such as deterioration of } \\
\text { vision, distorted vision, blurred vision } \\
\text { and/or floaters, an examination should } \\
\text { be carried out promptly at the } \\
\text { ophthalmologist's. }\end{array}$ \\
\hline $\begin{array}{l}\text { Estimation of macro- } \\
\text { and microvascular } \\
\text { overall risk }\end{array}$ & $\begin{array}{l}\text { People with type } 2 \text { diabetes should be } \\
\text { examined for vascular risks (hypertension) } \\
\text { at least once a year and they should be } \\
\text { asked whether they smoke. In addition, } \\
\text { HbA1c, lipids, uric acid and circulatory } \\
\text { parameters (blood pressure measurement } \\
\text { and pulse measurement at different sites) } \\
\text { should be controlled and a micro-l } \\
\text { macroalbuminuria should be measured } \\
\text { quantitatively. Looking for symptoms of } \\
\text { heart insufficiency should be done at least } \\
\text { twice a year. }\end{array}$ \\
\hline
\end{tabular}

Intensive lifestyle intervention, including an extensive sports and exercise programme, did not lead to better cardiovascular endpoints in the large mean RCT of 9.6 years [26]. The difference between the intensive lifestyle intervention group and the control group at the end of the study was only $2.5 \%$ of body weight. Nevertheless, the study participants profited from a significantly improved vascular risk profile, better physical fitness and mobility, improvement of depression, sleep apnoea and quality of life. In the long term, better physical fitness and weight reduction or stabilization can be better maintained [27]. In a post-hoc analysis of the Look-AHEAD study, participants in the intensified lifestyle intervention who lost $\geq 10 \%$ or more of their body weight had a $20 \%$ lower risk for the primary endpoint (cardiovascular death, non-fatal heart attack, non-fatal stroke, hospitalization for angina pectoris); adjusted HR 0.80; $95 \% \mathrm{Cl} 0.65-0.99 ; \mathrm{p}=0.039$ ) and a $2 \%$ risk reduction for the secondary endpoint (all-cause mortality, coronary bypass, percutaneous coronary intervention, carotid endarterectomy, hospitalization for cardiac insufficiency; adjusted HR 0.79; $95 \% \mathrm{Cl} 0.66-0.95 ; \mathrm{p}=0.011$ ) [28]. The disability-free, but not
- Table 4 Situations in which plasma glucose self-monitoring is necessary or may be temporarily necessary in people with type 2 diabetes ${ }^{1}$.

\begin{tabular}{|c|c|}
\hline & Clinically defined situations \\
\hline Diabetes stage & - Newly diagnosed, adjustment phase \\
\hline $\begin{array}{l}\text { Diabetes along its } \\
\text { course }\end{array}$ & $\begin{array}{l}\text { - Unstable with frequent hypoglycaemia (at } \\
\text { this point, measure before all meals until } \\
\text { the therapy goal is achieved, then return to } \\
\text { targeted situational measurements) } \\
\text { - Therapy intensification } \\
\text { - Temporarliy after switching from insulin to } \\
\text { oral antidiabetic therapy }\end{array}$ \\
\hline $\begin{array}{l}\text { Additional illnesses/ } \\
\text { interventions }\end{array}$ & $\begin{array}{l}\text { - Serious infections } \\
\text { - Planned operations } \\
\text { - Mental illnesses with unreliable intake of } \\
\text { medication } \\
\text { - During sport/exercise and blood glucose- } \\
\text { lowering substances, which may be } \\
\text { associated with hypoglycaemia, and } \\
\text { corresponding symptoms occur } \\
\text { - Acute changes in diet due to illness (e.g. } \\
\text { diarrhoea/vomiting) }\end{array}$ \\
\hline Diabetes therapy & $\begin{array}{l}\text { - Oral antidiabetics (OAD) with hypoglycae- } \\
\text { mia potential (sulfonylureas, glinides, then } \\
\text { occasional measurements) } \\
\text { - Insulin therapy and necessity of insulin } \\
\text { dose self-adjustment } \\
\text { - Intensified conventional insulin therapy } \\
\text { (before all meals, occasionally at night) } \\
\text { - Insulin pump therapy (before all meals, } \\
\text { occasionally at night) } \\
\text { - Situations with special hazards (e.g. shift } \\
\text { work, driving lorries, buses, cranes, etc.) }\end{array}$ \\
\hline \multicolumn{2}{|c|}{$\begin{array}{l}1 \text { G-BA decision of June 16, } 2016 \text { (BAnz AT 06.09.2016 B3): } \\
\text { Continuous interstitial glucose measurements with real-time } \\
\text { measuring devices (rtCGM) for therapy control in patients with } \\
\text { insulin-dependent diabetes mellitus can be provided under special } \\
\text { conditions as contracted medical services at the expense of the } \\
\text { health insurance funds. }\end{array}$} \\
\hline
\end{tabular}

the total life expectancy was extended in the Look-AHEAD intervention [29].

Physical activity is especially beneficial for people with type 2 diabetes for a number of reasons [30-32].

\section{Cessation of smoking}

Active and passive smoking is not only an avoidable cause of significantly increased morbidity and mortality, it is also a significant risk factor for type 2 diabetes [33].

Smokers should therefore always be informed about the particular risks of smoking for type 2 diabetes, microvascular and macrovascular complications and lung diseases and should be given specific advice whenever this appears appropriate to the situation. They should be urged to give up tobacco smoking.

Smokers wishing to change their smoking habits should be given regular advice on possible methods of cessation ( $>$ Fig. 2 ). 


\section{Type 2 diabetes \\ and/or \\ additional cardiovascular risk factors}

\section{Lifestyle measures: \\ Increasing physical activity and improving cardiovascular fitness}

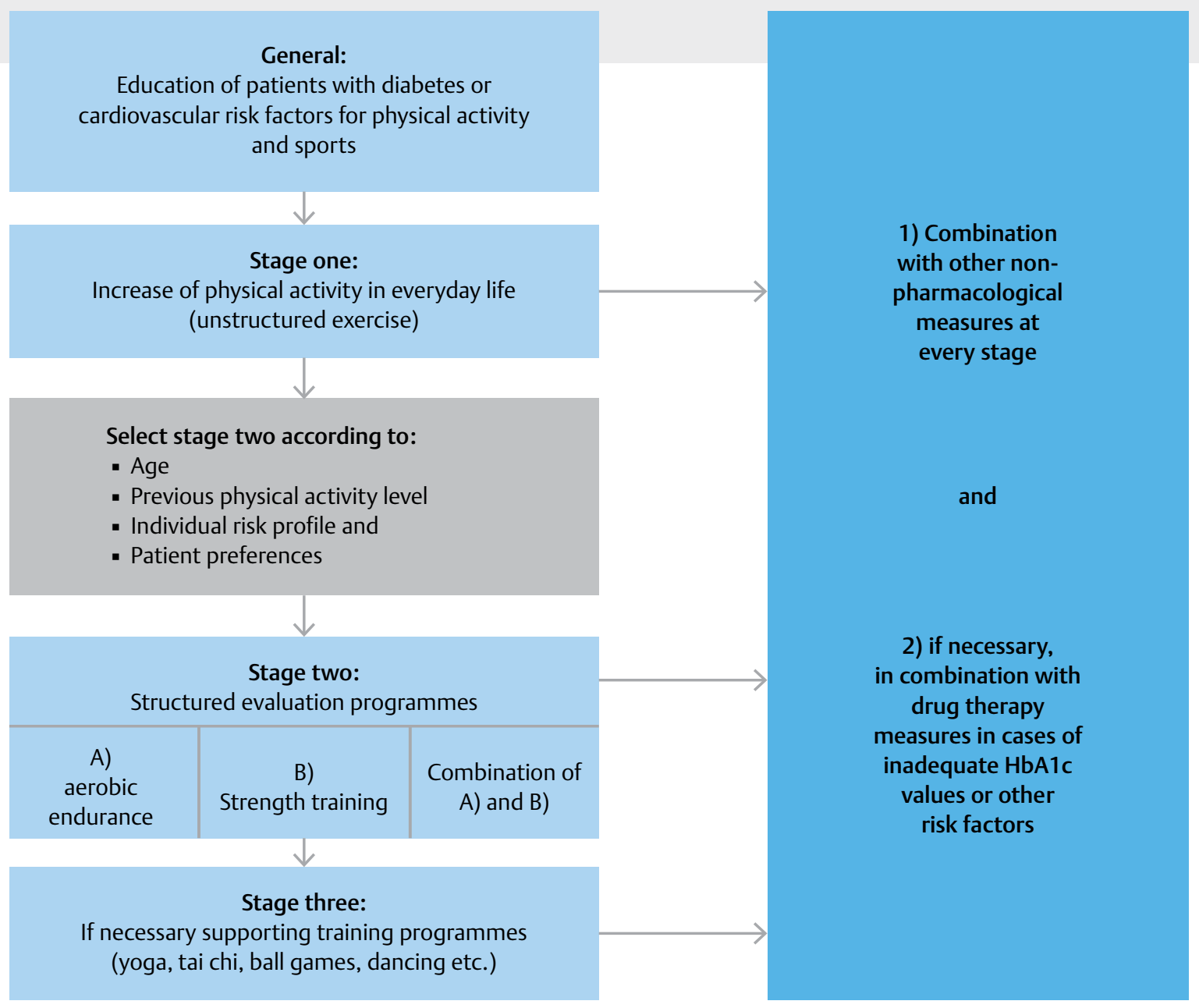

- Fig. 1 Step-by-step programme of physical activity. Source: German Medical Association/Bundesärztekammer (BÄK), National Association of Statutory Health Insurance Physicians/Kassenärztliche Bundesvereinigung (KBV), German Association of the Scientific Medical Professional Societies/ Arbeitsgemeinschaft der Wissenschaftlichen Medizinischen Fachgesellschaften (AWMF). National Treatment Guideline for Type 2 Diabetes, long version/Nationale Versorgungsleitlinie Therapie des Typ-2-Diabetes - Langfassung, first edition. Version 4. 2013, last modified: November 2014. Available from: www.dm-therapie.versorgungsleitlinien.de; [cited: 05.09.2019]. doi:10.6101/AZQ/000 213 [rerif].

\section{Pharmacotherapy}

The step-by-step procedure provided in the therapy algorithm ( Figs. 3,4 ) refers to the time of clinical diagnosis of type 2 diabetes in the stage of relative metabolic compensation. Newly diagnosed patients with metabolic decompensation should receive basic therapy and pharmacotherapy at the same time.
The alphabetical listing of oral antidiabetic drugs after metformin was deliberately chosen because all drugs have advantages and disadvantages which depending on the multimorbidity and patient preferences have to be discussed with each patient with type 2 diabetes. 


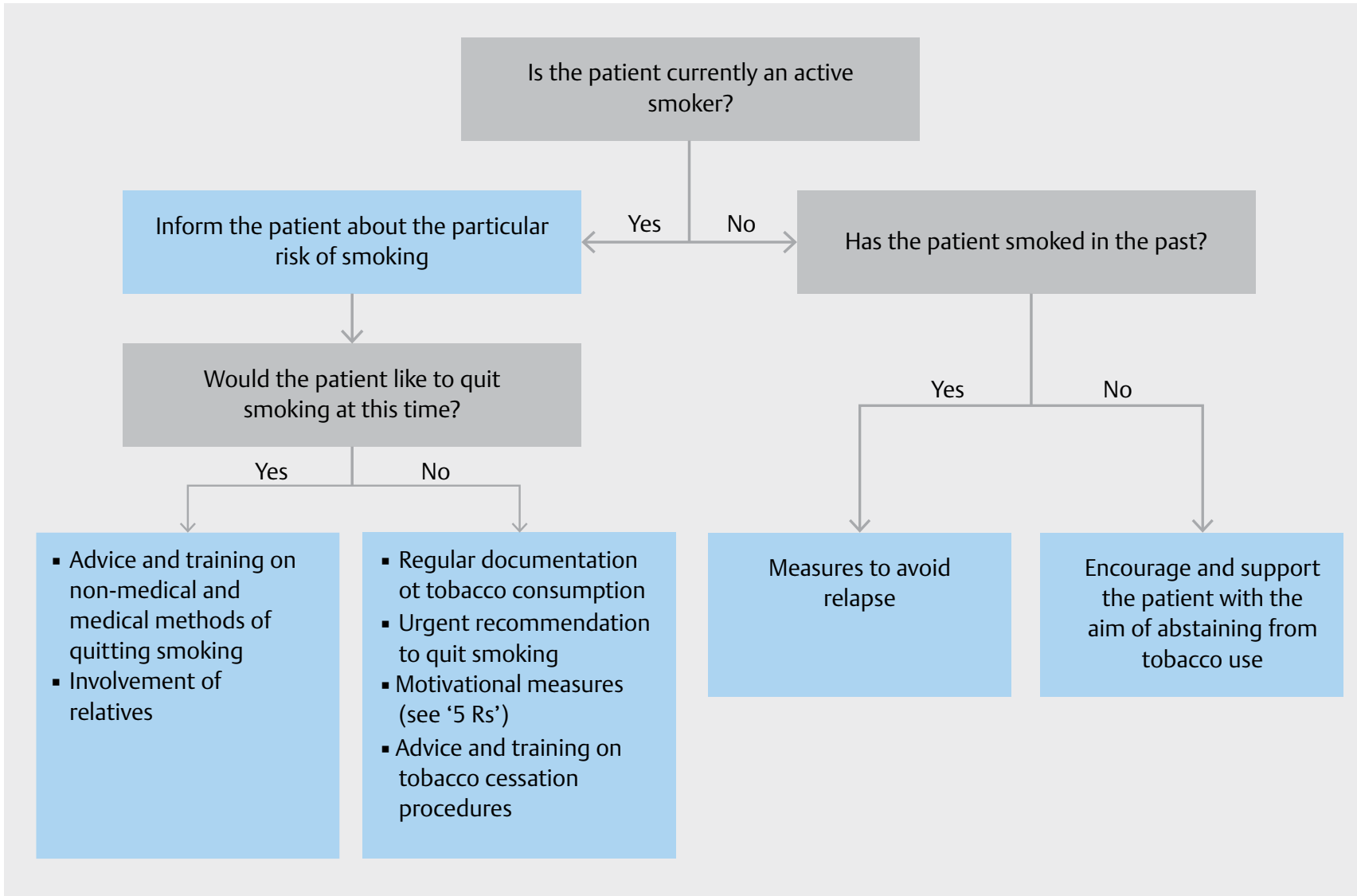

-Fig. 2 Algorithm for the procedure of tobacco cessation. Source: German Medical Association/Bundesärztekammer (BÄK), National Association of Statutory Health Insurance Physicians/Kassenärztliche Bundesvereinigung (KBV), German Association of the Scientific Medical Professional Societies/ Arbeitsgemeinschaft der Wissenschaftlichen Medizinischen Fachgesellschaften (AWMF). National Treatment Guideline for Type 2 Diabetes, long version/Nationale Versorgungsleitlinie Therapie des Typ-2-Diabetes - Langfassung, first edition. [cited: 15.08.2018]. doi:10.6101/AZQ/000 213 [rerif].

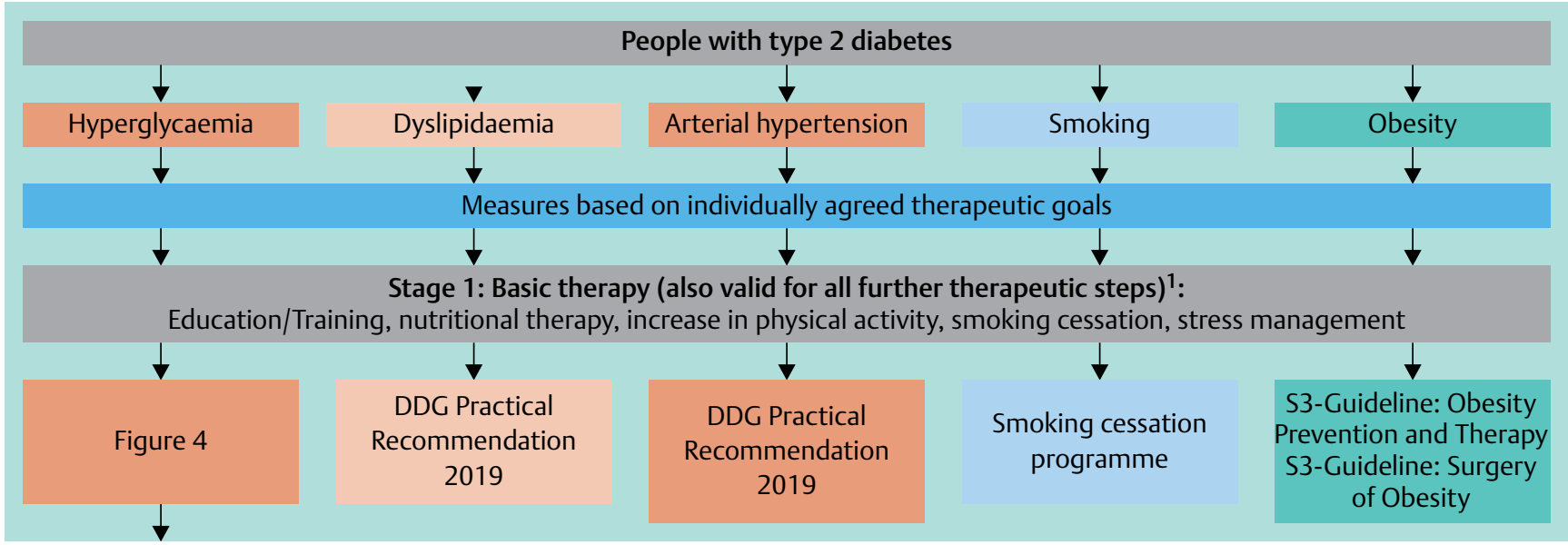

-Fig. 3 Therapy algorithm for type 2 diabetes. 1 Lifestyle modifying, non-pharmacological therapy measures represent the basic therapy at all therapeutic steps levels but are often insufficient on their own. For patients who do not exhibit signs of success using lifestyle modification measures (due to the degree of severity of the metabolic derangement, adherence problems, multimorbidity), these measures should be combined with metformin and if contraindications or side effects exist with another antidiabetic drug [rerif]. 


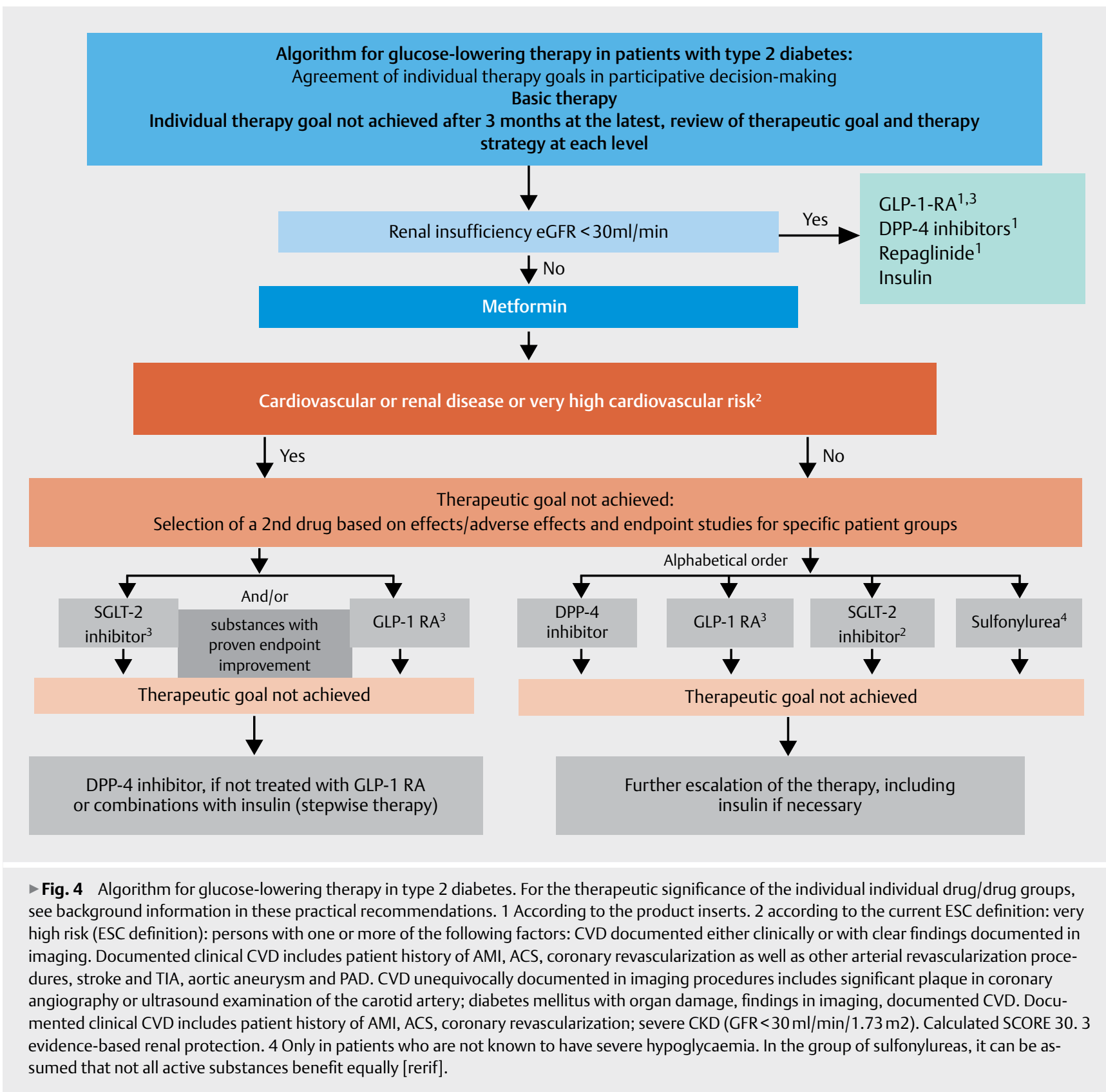

At the same time, all antidiabetics show varying degrees of evidence for patient-relevant endpoints. This means that there are primary or secondary classifications of glucose-lowering drugs which have a significant influence on the treatment decision based on the patient's characteristics (very high vascular risk profile or manifested cardiovascular and/or renal complications, tendency to hypoglycaemia, severely overweight and evidence-based studies).

\section{Metformin}

Thanks to its good efficacy in reducing HbA1c, known safety profile, long experience and low cost, metformin is currently the firstchoice antidiabetic for the treatment of type 2 diabetes. Other advantages are the low risk of hypoglycaemia (warning: when con- suming alcohol at the same time) and the advantageous effect of slightly reducing weight.

The indication of mono- and combination therapy with metformin was extended in February 2017 due to extensive publications [34]:

- Patients up to a renal insufficiency CKD $3 b$ (>eGFR $30 \mathrm{ml} / \mathrm{min}$ ) can be treated with metformin if there are no other contraindications.

- Maximum daily dose is $1000 \mathrm{mg}$ (500-0-500 mg) for an eGFR of 30-44 ml/min. At this eGFR, a metformin therapy should not be started newly.

- Maximum daily dose is $2000 \mathrm{mg}$ for an eGFR of $45-59 \mathrm{ml} / \mathrm{min}$.

- To be on the safe side, a dose reduction to $500 \mathrm{mg}$ per day can be carried out at an eGFR of 30-44 ml/min, because the eGFR 
can be worsen acutely at this level, patricularly in elderly people with exsiccosis or due to kidney toxic drugs.

The pros and cons of metformin therapy at this eGFR must be explained to the patient.

In the population-based large study involving 75413 patients of the Geisinger Health System, an analysis of all patients with regard to hospitalisation due to acidosis was carried out. 2335 hospitalizations due to acidosis were found in the period from 2004 to 2017 (mean follow-up time of 5.7 years). In this clinical real-world setting and compared to other antidiabetic drugs (excluding insulin), metformin was only associated with lactate acidosis if the eGFR was lower than $<30 \mathrm{ml} / \mathrm{min}$ [35].

As far as clinical endpoints are concerned, despite the frequent use of metformin, the data are inconclusive. Positive data from the UKPDS can be found in a relatively small number of overweight patients and from several small studies. In a recent meta-analysis, neither significant positive nor negative effects of metformin on cardiovascular endpoints were found [36]; however, the authors admit that the numbers are too small small for a meta-analysis and a large controlled study would be necessary to clarify the question. Correspondingly, there is no evidence of an advantage of metformin for a given combination therapy with respect to cardiovascular endpoints and all-cause mortality $[37,38]$.

Metformin is currently gaining great interest due to interesting pleiotropic effects that influence changes at the epigenetic level and gene expression and are thus potentially protective against carcinomas [39-44].

Summary of the therapy with metformin:

- Kidney function must be checked regularly (every 3-6 months). Warning: Metformin must be discontinued immediately if eGFR drops to $<30 \mathrm{ml} / \mathrm{min}$.

- Beware of diseases which increase the risk of lactic acidosis

(e. g. acute deterioration of kidney function due to gastroenteritis, respiratory insufficiency, acute diseases and infections or non-steroidal anti-inflammatory drugs).

- Caution when initiating therapy with ACE inhibitors or AT-1 receptor blockers, diuretics, at the beginning of therapy with non-steroidal anti-inflammatory drugs.

- When administering x-ray contrast media, prior to interventional or major surgical procedures, the patient should discontinue the use of metformin and only restart taking it after $48 \mathrm{~h}$, and only if the eGFR has not deteriorated significantly postoperatively and the patient can eat again.

\section{Sulphonylureas}

Sulfonylureas have been used for decades because they effectively lower blood glucose, are well tolerated and are inexpensive.Due to their ability to increase insulin secretion independently of glucose, they have the highest hypoglycaemia potential of all oral antidiabetics with the risk of severe and prolonged hypoglycaemia, especially in elderly people with impaired kidney function and polypharmacy. Sulfonylureas are largely contraindicated with decreasing renal function (eGFR $<30 \mathrm{ml} / \mathrm{min}$ ) with the exception of gliclazide and gliquidone. Due to the high risk of severe hypoglycaemia in patients with cardiovascular and renal complications, sulfonylureas should not be used in these people. Sulfonylureas usually lead to moderate weight gain.

Favourable effects on microvascular endpoints were found in the UKPDS more than 6 years after treatment initiation for chlorpropramide and glibenclamide (mainly reduced rate of photocoagulation). The ADVANCE study found positive effects for gliclazide on microvascular complications [43].

In the recently published CAROLINA study, a prospective, randomized, controlled study (observation period approx. 5 years, in each study arm approx. 3000 patients) linagliptin (5 mg/d) and glimepiride (1-4 mg/d) were compared with regard to cardiovascular endpoints, hypoglycaemia and body weight [45]. There was no difference in the comparison of the two study arms for 3P-MACE, 4PMACE, total and cardiovascular morbidity and mortality with comparable HbA1c [46]. Weight was more favourable under linagliptin compared to glimepiride $(-1.5 \mathrm{~kg})$ and rates of all, moderate, severe and hospitalization for hypoglycemia were significantly lower under linagliptin compared to glimepiride (HR 0.23; $95 \% \mathrm{Cl}$ 0.21-0.26; $\mathrm{p}<0.0001$, HR 0.18; $95 \% \mathrm{Cl} 0.15-0.21$; $<0.0001), \mathrm{HR}$ 0.15 ; $95 \%$ Cl 0.08-0.29; $\mathrm{p}<0.0001$, HR 0.07; $95 \% \mathrm{Cl} 0.02-0.31$; $\mathrm{P}=0.0004$; resp.). The authors concluded from the data of the CAROLINA study that there are no other reasons than cost reasons to use glimepiride more preferentially than linagliptin in antidiabetic therapy.

In several retrospective observational studies, analyses from register data and their meta-analyses as well as Cochrane reviews it was shown that sulfonylureas have no benefit on macrovascular endpoints, neither in mono- nor in combination therapy. Rather, increased cardiovascular morbidity and mortality were described [38, 47-54].

\section{Repaglinide}

Based on a Federal Joint Committee (G-BA) decision, a comprehensive limitation of the prescribability of glinides was introduced as of July 1,2016 . The prescribability restriction is as follows:

\section{"Repaglinide therapy is only allowed for patients with renal insufficiency $(<25 \mathrm{ml} / \mathrm{min})$ unless other oral antidiabetics und insulin therapy are not indicated."}

Despite a detailed evidence-based statement (see also http://www. deutsche-diabetes-gesellschaft.de/stellungnahmen) to the G-BA and BMG, the G-BA decision remains valid.

\section{DPP-4 inhibitors}

DPP-4 inhibitors are increasingly replacing the therapy with sulfonylureas. The reasons are a favourable safety profile even in progressive renal insufficiency and a good tolerability, which is particularly important for elderly people. With the exception of linagliptin, the dosage of all DPP-4 inhibitors on the market must be adapted to the kidney function. In addition, DPP-4 inhibitors show largely weight-neutral effects with similar antihyperglycaemic effects and low hypoglycaemic rates. DPP-4 inhibitors seem to exert better metabolic control for longer than sulfonylureas (observation period 104 weeks) [55]. However, a longer beta-cell reserve under linagliptin cannot be clearly proven in the CAROLINA study [55]. 
The results of the RCTs SAVOR TIMI $53^{\circledR}$ (saxagliptin [56]), EXAMINE $^{\circledR}$ (alogliptin [57]), TECOS $^{\circledR}$ (sitagliptin [58]), CARMELINA ${ }^{\circledR}$ (linagliptin [59]) on the effect of DPP-4 inhibitors on cardiovascular and renal endpoints each show cardiovascular safety of the investigated DPP-4 inhibitor in their primary endpoints, which was also confirmed in extensive meta-analyses [60-66]. DPP-4 inhibitors are therefore effective antidiabetics with few side effects and can be used very well as mono- and combination therapy if contraindications to the use of metformin are present and there is a corresponding patient preference.

Hospitalization for heart failure was not increased with DPP-4 inhibitors except for saxagliptin (SAVOR TIMI 53). In an extensive meta-analysis of the risk of DPP-4 inhibitors for heart failure or hospitalization due to heart failure, including RCTs and observational studies, the authors concluded that the effect of DPP-4 inhibitors on heart failure remains uncertain (due to relatively short observation times and overall weak database).

The meta-analysis of the 3 RCTs with DPP-4 inhibitors (SAVOR TIMI 53, EXAMINE and TECOS) showed an increased incidence of acute pancreatitis compared to corresponding controls (Odds ratio 1.79; $95 \% \mathrm{Cl} 1.13-2.82 ; \mathrm{p}=0.013$ ), whereby the absolute risk of acute pancreatitis was low overall and only $0.13 \%$ higher in absolute terms among DPP-4 inhibitors [67]. Yet DPP-4 inhibitors should avoided in patients with a history of or risks for pancreatitis.

In an extensive population-based study, DPP-4 inhibitors were associated with a significantly higher incidence of inflammatory bowel disease in type 2 diabetes (HR 1.75; $95 \%$ Cl 1.22-2.49) [68]. This association was highest 3-4 years after therapy with DPP-4 inhibitors but was significantly lower thereafter. The association started 2-4 years after the beginning of the therapy. In a recent meta-analysis of 13 studies, however, no association was found between DPP-4 inhibitors and inflammatory bowel diseases [69].

In combination with metformin, sitagliptin was certified by the G-BA as having a low additional benefit (BAnz AT 29.04.2019). Saxagliptin however neither in the mono- nor in a combination therapy showed an additioan benefit (BAnz AT 18.01.2017, BAnz AT 13.03.2018 B2).

\section{SGLT-2 inhibitors}

SGLT-2 inhibitors (canagliflozin, dapagliflozin, empagliflozine, ertugliflozin) are effective antihyperglycaemic substances in the treatment of type 2 diabetes in both mono- and combination therapy with all other glucose-lowering drugs. Their efficacy profile is favourable, also because the risk of hypoglycaemia is low, patients lose weight and there is a clinically relevant reduction in systolic blood pressure [70-77]. They also significantly reduce cardiovascular and renal endpoints (see below).

However, there is a significantly increased risk of genital infections with SGLT-2 inhibitors in RCTs $[78,79]$. The relative risk of SGLT-2 inhibitors for genital infections was more than 3 times higher than placebo (RR 3.37; $95 \% \mathrm{Cl} 2.89-3.93$ ) and almost 4 times higher than an active comparator (RR 3.89; $95 \% \mathrm{Cl} 3.14-4.82$ ). By contrast, the risk of urinary tract infections was not significantly increased by SGLT-2 inhibitors compared to placebo (RR 1.03; $95 \%$ $\mathrm{Cl} 0.96-1.11$ ) or an active comparator therapy (RR $1.08 ; 95 \% \mathrm{Cl}$ $0.93-1.25)$.
Ertugliflozine (VERTIS mono study [80]) is approved in Germany only in a fixed combination with sitagliptin (VERTIS Factorial Study [81]). According to the decision of the G-BA of November 01, 2018, there is no additional benefit of this fixed combination.

In the use of SGLT-2 inhibitors, ketoacidosis was occasionally observed in people with type 2 diabetes [82, 83]. The SGLT-2 inhibitor manufacturers in Germany informed physicians and pharmacists about this issue on July 9, 2015.

An extensive analysis of all reports on ketoacidosis with a possible association of SGLT-2 inhibitors with ketacidosis listed in the US Food and Drug Administration Adverse Event Reporting System (FAERS) between January 2014 and October 2016 has been published [84]. A PPR of 7.9 (95\% Cl 7.5-8.4) was found. The proportional reporting ratio (PRR) is the ratio of spontaneous reports for a given drug (in this case SGLT-2 inhibitors) associated with a specific side effect (here, ketoacidosis) divided by the corresponding ratio for all or some other drugs with this side effect. However, PPR does not describe a relative risk, i. e. the real risk for ketoacidosis, and therefore cannot be used in clinical practice. The detailed analysis of 2397 reports of ketoacidosis in FAERS showed a dominance in people with type 1 diabetes, in women, in a wide age and body weight range and a high variability in the duration of SGLT- 2 inhibitor therapy. 37 people (1.54\%) died of ketoacidosis. In the large randomized controlled trials with SGLT-2 inhibitors, the risk of ketoacidosis among SGLT-2 inhibitors was significantly increased in type 2 diabetes, but below $1 \%$.

Normoglycaemia or mild hyperglycaemia does not exclude a ketoacidosis with SGLT-2 inhibitors. Risk factors for the development of a (euglycaemic) ketoacidosis with SGLT-2 inhibitors included a rapid and significant reduction of the insulin dose, severe dehydration and alcohol consumption; almost all patients with ketoacidosis were in a catabolic state (operations, myocardial infarction, severe infections, long fasting, excessive physical strain).

Therefore, the DDG recommends, as does the ADA, that the following be considered when dealing with SGLT-2 inhibitors:

- SGLT-2 inhibitors must be discontinued $24 \mathrm{~h}$ prior to a major elective surgery,

- Immediate interruption of SGLT-2 inhibitor therapy in emergency cases and acute diseases,

- Caution during ongoing insulin therapy (avoid significant reduction or discontinuation of insulin therapy),

- Avoidance of ketogenic/extremely low carbohydrate foods and excessive alcohol consumption,

- The combination of SGLT-2 inhibitors with metformin increases the risk of ketoacidosis [85] and

- If symptoms are present, consider the possibility of ketoacidosis and initiate the appropriate diagnostic procedure (at least plasma glucose and ketones in the urine, possibly also necessary blood gas analysis).

The effects of SGLT-2 inhibitor therapy on clinical endpoints were investigated for empagliflozin in a large RCT published in 2015 (EMPA-REG OUTCOME study [86]). Patients with type 2 diabetes and already manifested cardiovascular diseases showed fewer cardiovascular events ( 10.5 vs. $12.1 \%$; HR 0.86; $95 \% \mathrm{Cl} 0.74-0.99$; $\mathrm{p}<0.04$ for superiority) during an observation period of 3.1 years on average with empagliflozin compared to placebo. There was no 
difference in the rate of myocardial infarction and stroke, but a significantly lower event rate for cardiovascular mortality (3.7 vs. 4.1\%; HR 0.62; $95 \%$ Cl 0.49-0.77; HR 0.49-p<0.001); for all-cause mortality (5.7 vs. 8.3\%; HR 0.68; $95 \% \mathrm{Cl} 0.57-0.82$; p<0.001) and hospitalization for heart failure (2.7 vs. $4.1 \%$; HR 0.65; $95 \% \mathrm{Cl} 0.50-$ 0.85; $\mathrm{p}=0.002$ ).

Further analyses of the EMPA-REG OUTCOME study [87] showed that empagliflozin slows the development and progression of nephropathy in patients with an eGFR initial of $\geq 30 \mathrm{ml} / \mathrm{min}$ : beginning or progression of nephropathy with empagliflozin compared to standard therapy (12.7 vs. $18.8 \%$; HR 0.61 ; $95 \%$ Cl $0.53-0.70$; $\mathrm{p}<0.001)$.

The post-hoc renal endpoint (doubling of S-creatinine, renal replacement therapy, or death from kidney disease) was significantly lower for empagliflozin compared to placebo (HR 0.54; $95 \% \mathrm{Cl}$ $0.40-0.75 ; p<0.001)$. In an analysis of the short-term and longterm effects ( 164 weeks) of empagliflozin on albumin excretion, a significant reduction of $22 \%$ on average in the microalbuminuria group and $29 \%$ in the macroalbuminuria cohort was observed [88], irrespective of the level of initial albuminuria.

Thus, the positive effect of the SGLT-2 inhibitor empagliflozin on cardiovascular and renal endpoints in a corresponding risk population has been convincingly demonstrated. The underlying mechanisms of cardiac and renal production of empagliflozin are the subject of extensive studies $[89,90]$.

In 2016, the G-BA certified empagliflozin in the benefit assessment in combination therapy with metformin a considerable additional benefit in patients with type 2 diabetes with manifested cardiovascular disease (https://www.g-ba.de/downloads/39-2612 694/2016-09-01_AM-RL-XII_Empagliflozin_D-214_BAnz.pdf). Accordingly, this additional benefit was included in the relaunches of the disease management programme for type 2 diabetes in April 2017 [91].

Current outcome RCT data on canagliflozin [92] (CANVAS programme) show the same tendency, namely a significant reduction in the composite endpoint (cardiovascular death, non-fatal myocardial infarction, and stroke) by $14 \%$ (HR 0.86; 95\%-KI 0.75-0.97) compared to placebo, decrease of the hospitalization rate due to heart failure by $33 \%$ (HR $0.67 ; 95 \% \mathrm{Cl} 0.52-0.87$ ) and renal outcome data with a reduction of the progression of albuminuria by $27 \%$ (HR 0.73; $95 \% \mathrm{Cl} 0.67-0.79$ ) and the composite endpoint (40\% reduction of eGFR, renal replacement therapy, renal death) by $40 \%$ (HR 0.60; $95 \% \mathrm{Cl} 0.47-0.77)$. Another large RCT was performed with canagliflozin in relation to a primary combined renal endpoint [93]. The patients already had renal insufficiency, a significant proteinuria at randomisation and had to be treated with an ACE-inhibitor or $\mathrm{AT}_{1}$-antagonist. Canagliflozin ( $100 \mathrm{mg}$ per day) significantly reduce clinically relevant endpoints compared to the control group.

Canagliflozin is currently not available on the German market despite the positive patient-relevant endpoints.

The DECLARE-TIMI 58 study with dapagliflozin [94] included 6974 patients (40.6\%) with known cardiovascular diseases and 10 186 (59.4\%) with multiple risk factors for arteriosclerotic cardiovascular diseases. The mean follow-up of the patients was 4.2 years. A total of 3962 patients stopped the study prematurely ( $=5.7 \%$ per year): 1811 of the 8574 patients (21.1\%) on dapagliflozin and
2151 of 8569 (25.1\%) in the control group. Dapagliflozin resulted in a significantly lower hospitalization rate for heart failure compared to placebo (HR 0.73; $95 \% \mathrm{Cl} 0.61-0.88$ ). There was no difference between the dapagliflozin group and the placebo group in the rate of 3P-MACE (8.8 vs. 9.4\%; HR 0.93; $95 \% \mathrm{Cl} 0.84-1.03$; $\mathrm{p}=0.17)$, cardiovascular morality (HR 0.98, $95 \% \mathrm{Cl} 0.82-1.17)$ and all-cause mortality (HR 0.93, $95 \% \mathrm{Cl} 0.82-1.04)$. In the renal composite secondary endpoint ( $\geq 40 \%$ reduction in eGFR, newly developed terminal renal failure or death of renal or cardiac genesis), dapagliflozin led to a significant reduction in renal endpoints (HR 0.76; $95 \%$ Cl 0.67-0.87).

Extensive sub-analyses of the DECLARE-TIMI 58 population confirmed the beneficial effects of dapagliflozin on the development and progression of renal [95] and cardiovascular endpoints [96, 97].

The European Medicines Agency (EMA) has launched a review process to investigate whether treatment with canagliflozin leads to an increased rate of amputations (usually toes):

On July 8, 2016, the Pharmacovigilance Risk Assessment Committee (PRAC) of the EMA extended the review to dapagliflozin and empagliflozin [98].

The canagliflozin studies CANVAS programme [92] confirms the assumption of a higher risk of amputations (mainly in the toe and metatarsal area) with canagliflozin compared to placebo (event rate 6.3 vs. 3.4 persons per 1000 patient years; $\mathrm{HR} 1.97 ; 95 \% \mathrm{CI}$ $1.41-2.75 ; p<0.001)$. The data on SGLT- inhibitors with respect to an increased rate of amputations in RCTs, higher amputation rates are also found in pharmacovigilance reports [99]. However, current studies and research did not find higher amputation rates under dapagliflozin [100] and empagliflozin [101], and the large CREDENCE study with canagliflozin also found no sign of an increased amputation rate.

The FDA has also issued a warning of an increased fracture risk due to reduced bone density under canagliflozin (www.fda.gov/ Drugs/DrugSafety/ucm461 449.htm). Indeed, the fracture event rate was significantly higher under canagliflozin compared to placebo: 15.4 vs. 11.9 per 1000 patient years $(p=0.02)$ [92]. In the recently published large RCT (CREDENCE study) with canagliflozin, however, no sign of an increased risk for fractures was found [93]. The careful elaboration of the CANVAS and CANVAS-R data showed a significant heterogeneity of the fracture risk in both studies: in the CANVAS study ( $n=4330$ : HR 1.55; $95 \% \mathrm{Cl} 1.21-1.97$ ) the risk was significantly increased, whereas this could not be proven in the CANVAS-R study ( $n=5812$ : HR 0.86; $95 \%$ Cl 0.62-1.19) [102].

A recent fracture analysis of people with type 2 diabetes $(n \geq 12$ 000 ) treated with empagliflozin (pooled data from placebo-controlled studies and a head-to-head study vs. glimepiride) did not reveal a significantly increased rate of fractures [103]. Two metaanalyses also showed no significant increase in fracture rates under therapy with SGLT-2 inhibitors, although the time of oberservation and follow-up were relatively short and the incidence rates for fractures were very low $[104,105]$.

A necrotizing fasciitis of the perineum and genitals (Fournier gangrene) is a very rare, severe infection with the need for immediate antibiotic and usually surgical intervention. Diabetes is one of the risk factors. With the introduction of SGLT-2 inhibitor therapy, a few cases of Fournier gangrene under empagliflozin therapy were described. On January 21, 2019, a Red Hand letter 
was published in consultation with the European Medicines Agency (EMA) and the Federal Institute for Drugs and Medical Products/ Bundesinstitut für Arzneimittel und Medizinprodukte (BfArM) to clarify the 'Risk of a Fournier gangrene (necrotizing fasciitis of the perineum) when using SCLT-2 inhibitors ('sodium glucose cotransporter-2 inhibitors")". Patients should be informed about this rare complication and adverse drug reactions should be reported (www. bfarm.de - Arzneimittel-Pharmakovigilanz- Risiken).

\section{GLP-1 receptor agonists}

GLP-1-RAs are antidiabetic drugs for the subcutaneous therapy of type 2 diabetes. Soon also an oral GLP-1 RA becomes available.

They can lower plasma glucose more on average than oral antidiabetics and also have blood pressure-lowering (slight), weightreducing [106] and specific cardio- and renal protective (see below) effects. If the individual therapeutic objective is not achieved, GLP1-RAs are useful combination partners to metformin, other OADs (except DPP-4 inhibitors) and/or basal insulin. GLP-1-RAs themselves have a low hypoglycemic risk.

For the GLP-1 receptor agonist (RA) liraglutide, the RCT (LEADER study) showed positive effects on clinically relevant endpoints [107]. The follow-up of 9340 patients averaged 3.8 years. The combined primary endpoint (first event for cardiovascular death, nonfatal myocardial infarction, non-fatal stroke) was significantly lower for liraglutide compared to placebo (13 vs. $14.9 \%$; $\mathrm{HR} \mathrm{0.87;95 \%} \mathrm{CI}$ $0.78-0.97 ; p<0.001$ for non-inferiority and $p=0.01$ for superiority). Fewer patients died of cardiovascular reasons (4.7 vs. $6.0 \%$; HR 0.78 ; $95 \% \mathrm{Cl} 0.66-0.93 ; \mathrm{p}=0.007$ ). All-cause mortality under liraglutide was also lower (8.2 vs. 9.6\%; HR 0.85; $95 \%$ Cl 0.74-0.97; $\mathrm{p}=0.02$ ). For the first time, this made it possible to demonstrate a positive effect on patient-relevant endpoints with a GLP-1-RA in an RCT.

A sub-analysis of the LEADER study population showed that $72.5 \%$ of patients had a vascular disease at the beginning of the study. $23 \%$ of this subpopulation had polyvascular disease and $77 \%$ had monovascular disease. In a 54-month follow-up, liraglutide led to a reduction of MACE: in patients with polyvascular disease (HR $0.82 ; 95 \% \mathrm{Cl} 0.66-1.02$ ) and monovascular disease (HR 0.82; $95 \%$ Cl $0.71-0.95)$ compared to placebo. No positive effects of liraglutide were found in patients without vascular complications [108]. The same was found in an analysis by Marso et al. [109], which demonstrated a reduction of myocardial infarctions in patients with a high vascular risk using liraglutide.

The analysis of secondary renal endpoints in the LEADER study showed that liraglutide was associated with a lower rate of development and progression of the renal composite endpoint (HR 0.78; $95 \% \mathrm{Cl} 0.67-0.92 ; \mathrm{p}=0.003$ ) and persistence of macroalbuminuria (HR 0.74; $95 \% \mathrm{Cl} 0.60-0.91 ; \mathrm{p}=0.004)$ compared to placebo [110].

In its decision of January 17, 2019 (BAnz AT 22.03.2019 B5), the G-BA recognised an additional benefit of liraglutide and included it in the structured treatment programmes for type 2 diabetes.

The current meta-analysis by Kristensen et al. [111] found a significant reduction of MACE of $12 \%$ (HR 0.88; $95 \% \mathrm{CI} 0.82-0.94$; $\mathrm{p}<0.0001$ ) using GLP-1-RAs. Hazard ratios were 0.88 (95\% Cl $0.81-$ $0.96 ; \mathrm{p}=0.003$ ) for cardiovascular death and 0.84 (95\% Cl 0.76$0.93 ; \mathrm{p}<0.0001)$ for fatal and non-fatal stroke and $0.91(95 \% \mathrm{Cl}$
0.84-1.00); $\mathrm{p}=0.043)$ for non-fatal and fatal myocardial infarction. GLP-1-RA led to a $12 \%$ reduction in all-cause mortality (HR 0.88 ; $95 \% \mathrm{Cl} 0.83-0.95 ; \mathrm{p}=0.001)$ and a $9 \%$ reduction in hospitalization for heart failure (HR 0.91; $95 \% \mathrm{Cl} 0.83-0.99$; $p=0.028$ ). The composite renal endpoint (development of a new macroalbuminuria, reduction of eGFR, progression to terminal renal failure) decreased by $17 \%$ (HR 0.83 ; $95 \%$ Cl 0.78-0.89; $<<0.0001)$, which was mainly due to the reduction of albuminuria.

GLP-1-RA was not reported to increase the risk of hypoglycaemia, pancreatitis or pancreatic cancer.

The very detailed and critical meta-analysis by Liu et al. [112] also came to a comparable result. All-cause mortality was slightly lower among GLP-1-RAs compared to control therapies: OR 0.89 (95\% Cl 0.80-0.98).

The multi-centre (371 study centres in 24 countries), randomized, double-blind placebo-controlled study on the cardiorenal effects of dulaglutide therapy (REWIND study; $1.5 \mathrm{mg}$ s.c. weekly) was recently published [113]. Included were 9901 patients with type 2 diabetes (mean age 66 years, average HbA1c $7.2 \%$ ). This study differs from the previously published studies on the cardiovascular and renal outcome under GLP-1-RA in the following important points: Longer observational period (mean 5.4 years), $69 \%$ of the study participants had cardiovascular risk factors, but no clinically manifested cardiovascular pre-illnesses and the ratio between women and men was fairly balanced ( $46 \%$ women). Compared to placebo, dulaglutide was able to reduce the mean $\mathrm{HbA} 1 \mathrm{c}$ baseline value of $7.2 \%$ over the entire study (HbA1c: $-0.46 \%$ for dulaglutide, $+0.16 \%$ for placebo; body weight: $-2.95 \mathrm{~kg}$ dulaglutide, $-1.49 \mathrm{~kg}$ placebo). In addition, dulaglutide showed a reduction of the secondary combined microvascular endpoint (HR 0.87 ; $95 \% \mathrm{Cl} 0.79-0.95)$, with this reduction predominantly affecting the renal outcome (HR 0.85; $95 \% \mathrm{Cl} 0.77-0.93 ; \mathrm{p}=0.0004)$. The primary endpoint 3P-MACE was significantly lower with dulaglutide (HR 0.88; 95\% Cl 0.79-0.99; $\mathrm{p}=0.026$ ), as was the risk of non-fatal stroke (HR 0.76; $95 \% \mathrm{Cl} 0.61-0.95 ; \mathrm{p}=0.017)$. No risk reductions were found for the following endpoints: non-fatal and fatal myocardial infarction, fatal stroke, cardiovascular death, all-cause mortality, and hospitalization for heart failure. Compared to placebo, dulaglutide did not show any differences with regard to relevant side effects: Cancer (pancreatic, medullary thyroid carcinoma, other thyroid carcinomas), acute pancreatitis or pancreatic enzyme elevations, liver diseases, cardiac arrhythmias and hypoglycemic rate.

In an explorative analysis of the REWIND data [114] renal outcome data concerning dulaglutide, a significant risk reduction for the summarized renal endpoint (new macroalbuminuria, eGFR reduction of $\geq 30 \%$ or chronic renal replacement therapy; HR 0.85 ; $95 \% \mathrm{Cl} 0.77-0.93 ; \mathrm{p}=0.0004)$ was determined with the clearest effect with respect to the macroalbuminuria component (HR 0.77; $95 \% \mathrm{Cl} 0.68-0.87 ; \mathrm{p}<0.0001)$.

Safety and cardiorenal outcome data have been published for albiglutide [115, 116]. The cardiovascular endpoint data on albiglutide (HARMONY outcomes trial [117]) were analysed and published in 2018. At that time albiglutide had already been taken off the market worldwide (July 2017). In the HARMONY study, 9463 patients were included and randomized (albiglutide $30-50 \mathrm{mg}$, $n=4731$; placebo $n=4732$ ). The mean observation period was only 1.6 years. There was no evidence for a difference in the two study 
arms with regard to important side effects.In 3P-MACE, a significant risk reduction using albiglutide (HR 0.78; $95 \% \mathrm{Cl} 0.68-0.90$; non-inferiority $p=0.0001$, superiority $p=0.0006$ ) was already observed after this short study period.

In the EXSCEL study 14752 patients (73.1\% with cardiovascular disease) were treated at a mean of 3,2 years with 2.0 mg exenatide once a week. Patients with or without cardiovascular disease showed no significant difference in the incidence of MACE between those who received exenatide or a placebo. Critical for the evaluation of the effects in the EXSCEL study is the very high dropout rate of over $40 \%$. Compared to the control group, there were no differences in cardiovascular mortality, non-fatal or fatal myocardial infarction or stroke, hospitalization for heart failure and incidence of acute pancreatitis, pancreatic carcinoma, medullary thyroid carcinoma or other serious side effects [118].

In the recently published meta-analysis by Bethel et al. [119], the 4 large RCTs ELIXA (lixisenatide), LEADER (liraglutide), EXSCEL (exenatide once a week) and SUSTAIN 6 (semaglutide) were evaluated. Compared to placebo, GLP-1 RAs showed a significant risk reduction (HR 0.90; $95 \% \mathrm{Cl} 0.82-0.99 ; \mathrm{p}=0.033$ ) for the primary endpoint (cardiovascular mortality, non-fatal myocardial infarction, non-fatal stroke), a relative risk reduction (RRR) of $13 \%$ for cardiovascular mortality $(0.87 ; 95 \% \mathrm{Cl} 0.79-0.96 ; \mathrm{p}=0.007)$, and an RRR of $12 \%(0.88 ; 95 \% \mathrm{Cl} 0.81-0.95 ; \mathrm{p}=0.002)$ for all-cause mortality. However, the statistical heterogeneity between the studies was large. There were no significant reductions by GLP-1-RAs for non-fatal or fatal myocardial infarction, stroke, hospitalization due to unstable angina or heart failure. Semaglutide s.c. is now also available in Germany. The SUSTAIN-6 study demonstrated cardiovascular benefit by significantly reducing the primary endpoint 3PMACE compared to the control group. In patients with high cardiovascular risk, a significant reduction (HR 0.74; $95 \% \mathrm{Cl} 0.58-0.95$ ) was found in the semaglutide group compared to placebo for the primary endpoint (cardiovascular death, non-fatal myocardial infarction or non-fatal stroke) [120].

In the recently published post-hoc analysis of the SUSTAIN-6 study, a risk reduction of MACE was found for semaglutide once a week s.c. versus placebo in all study participants regardless of gender, age or cardiovascular risk profile at the start of the study [121]. In the PIONEER- 6 study, there was a significant reduction in cardiovascular death (HR 0.49; $95 \% \mathrm{Cl} 0.27-0.92$ ) and all-cause mortality (HR 0.51; $95 \% \mathrm{Cl} 0.31-0.84$ ) with oral semaglutide versus placebo [122]. In a recent meta-analysis, treatment with GLP-1-RAs or SGLT-2 inhibitors was associated with significantly lower allcause mortality compared to DPP-4 inhibitors or other antidiabetics or no therapy (HR $0.88 ; 95 \% \mathrm{Cl} 0.81-0.94$ or $\mathrm{HR} 0.80 ; 95 \% \mathrm{Cl}$ 0.71-0.89).

Similar data were found for cardiovascular mortality, myocardial infarction and heart failure in comparison to the control groups [123].

The meta-analysis of GLP-1-RAs exenatide, liraglutide, lixisenatide, albiglutide, dulaglutide and semaglutide published in 2017 showed a significant reduction in the incidence of nephropathy compared to other antidiabetics (OR 0.74; $95 \% \mathrm{Cl} 0.60-0.92$; $\mathrm{p}=0.005$ ). Retinopathy remained unchanged among GLP-1-RAs except for semaglutide, which had a negative effect on changes in the ocular fundus (OR 1.75; $95 \% \mathrm{Cl} 1.10-2.78 ; \mathrm{p}=0.018$ ) [124].
Whether this is related to the rapid optimisation of the metabolism is being discussed [125]. In addition, only patients with pre-existing retinopathy were affected. A corresponding study was initiated to clarify the retinopathy risk when using semaglutide (ClinicalTrials.gov number, NCT03 811 561).

\section{GLP-1 receptor agonists: pancreatitis, pancreatic} carcinoma and cholecystolithiasis

Of 113 studies included in the analysis by Monami et al., 13 found no data on pancreatitis. No pancreatitis or pancreatic cancer events were reported in 72 studies. In the remaining studies $(n=28)$, the incidence of pancreatitis and pancreatic carcinomas with GLP-1RAs was comparable with the comparative drugs (pancreatitis OR 0.93; $95 \%$ Cl 0.65-1.34; $\mathrm{p}=0.71$; pancreatic carcinomas OR 0.94; $95 \% \mathrm{Cl} 0.52-1.70 ; \mathrm{p}=0.84)$. However, the risk for gallstones was increased (OR 1.30; $95 \% \mathrm{Cl} 1.01-1.68 ; \mathrm{p}=0.041$ ) [126]. In the comprehensive analysis of RCTs with incretin-based therapies (SAVORTIMI 53 (saxagliptin), EXAMINE (alogliptin), TECOS (sitagiptin), which also took place in 2017, ELIXA (lixisenatide) and with liraglutide in LEADER and semaglutide in SUSTAIN-6 no significant risk increase for pancreatitis and pancreatic carcinoma for GLP-1-RA could be found in contrast to therapies with DPP-4 inhibitors [127].

In the meta-analysis published in 2018 by Bethel et al. [119], there were no differences in pancreatitis, pancreatic carcinoma and medullary thyroid carcinoma in patients treated with GLP-1-RA therapy compared to participants treated with placebo. In addition, the large multinational population-based cohort study with 1532513 patients included in the period from January 1, 2007 to June 30,2013 , and up to June 30,2014 , showed no association of a higher risk for pancreatitis among incretin-based therapies compared to OADs [128]. These data are consistent with the results of a meta-analysis of real-world data, which also found no evidence of a higher risk for pancreatitis among incretin-based therapies [129].

\section{Insulins}

With the manifold possibilities of oral antidiabetic therapy with or without combination with GLP-1-RAs, insulin therapy can in many cases be postponed to later stages of the disease. However, a necessary insulin administration should not then be delayed by years [130]. Insulin therapy can be easily combined with other antidiabetics, and the large number of insulins and injection aids facilitates individualisation of the therapy.

An extensive discussion on new insulins, however, would go far beyond the scope of these practical recommendations. Therefore, the authors have concentrated on a few aspects of new insulin preparations.

Basal insulin analogues: Insulin degludec $(n=3818)$ is not inferior to insulin glargin $100(n=3819)$ in the therapy of people with type 2 diabetes and a high risk of cardiovascular events in terms of MACE. The HbA1c values were identical in both groups over the observational period of 2 years $(7.5 \pm 1.2 \%)$, but the fasting plasma glucose values were significantly lower under insulin degludec. The hazard ratio was 0.91 ( $95 \% \mathrm{Cl} 0.78-1.06)$ for the primary endpoint (cardiovascular death, non-fatal myocardial infarction, non-fatal stroke). By contrast, the rate of severe hypoglycaemia (secondary endpoint) was significantly lower for insulin degludec (4.9\%) than 
for insulin glargin 100 (6.6\%) (hazard ratio 0.60; 95\% Cl 0.48-0.76; $p<0.001)$. The rate of severe side effects such as benign and malignant neoplasia was comparable (DEVOTE study [131]). In the DEVOTE study, it was shown once again that confirmed severe hypoglycaemia was associated with an increased rate of all-cause mortality in a period of 15-365 days before the clinical endpoint [132].

Pharmacokinetic and pharmacodynamic studies have shown that insulin glargin 300 has a flatter efficacy profile, lasts slightly longer and has a lower day-to-day variability than insulin glargin 100. Metabolic control was comparable for both insulin types, while the rate of nocturnal hypoglycaemia was significantly lower for insulin glargin 300 than for insulin glargin 100 [133-135].

Biosimilar insulin glargin 100: Pharmacokinetics and -dynamics are comparable for insulin glargin 100 and biosimilar insulin glargin 100 in humans without and with type 2 diabetes [136, 137]. In the meta-analysis by Yamada et al. [138] there were no differences between biosimilar insulins and the original insulins in relation to: HbA1c, fasting plasma glucose, hypoglycaemia, injection site reactions, insulin antibodies, allergic reactions and mortality.

When comparing different insulin analogues (insulin glargin and insulin degludec) with human insulin, a large cohort study from Denmark, Finland, Norway, Sweden and Great Britain found no evidence of an increased carcinoma risk, neither for insulin glargin nor for insulin degludec compared to human insulin for the 10 examined carcinomas in a mean observational period of 4.6 years [139].

Combination of long-acting insulin plus GLP-1-RA: The fixed combination of long-acting insulin plus GLP-1-RA (currently not available in Germany) or free simultaneous or consecutive combinations have advantages over intensive insulin therapy with prandial and basal insulin in terms of therapy adherence, rate of hypoglycaemia, weight progression and insulin usage. Compared to intensive insulin therapy, gastrointestinal side effects were more frequent with GLP-1-RA [140-142].

Fast-acting insulin analogues: Insulin lispro 200 shows potential advantages for a higher concentrated insulin especially in cases of severe insulin resistance (e. g. obesity), as less volume has to be injected with the same amount of insulin and economic advantages for the patient.

Compared to insulin lispro 100, insulin lispro 200 showed also significant improvements in variability of fasting glucose, HbA1c, hypoglycemic rate and satisfaction with therapy. At the same time, $20 \%$ insulin could be saved [143].

Ultra-fast insulin aspart is absorbed by the blood twice as fast and thus has an approximately $50 \%$ higher insulin effect with significantly lower postprandial blood glucose values, especially in the first 30 min after injection. The faster onset of action means that glucose is even better controllable, especially in people with type 1 diabetes and those on insulin pump therapy [144]. Ultra-fast insulin aspart showed a similar reduction of $\mathrm{HbA} 1 \mathrm{c}$ compared to insulin aspart in people with type 2 diabetes (observation time 26 weeks); the 1-hour postprandial glucose values were significantly lower after injection of fast insulin aspart, but not 2-4 $\mathrm{h}$ after a test meal. The total rates of severe hypoglycaemia were not different between the two insulins. However, the relative risk of hypoglycaemia 0-2 h postprandially was significantly higher with fast insulin aspart (RR 1.60; $95 \%$ Cl 1.13-2.27) [145].

\section{Arguments for therapy stage 1}

The basic therapy comprises all lifestyle-modifying, non-pharmacological measures. These include patient training and education, nutrition therapy, increasing physical activity and cessation of smoking (National Treatment Guideline (Nationale Versorgungsleitlinie NVL)) type 2 diabetes mellitus), as well as stress management strategies. One important goal is to strengthen the willpower to lead a healthy lifestyle (giving up smoking, a diet appropriate to diabetes, exercise, reducing alcohol consumption) (» Figs. 3,4). Digital aids and telemedical support are becoming increasingly important for the implementation of personalised basic therapy. As many people with type 2 diabetes have a variety of other vascular risk factors in addition to chronic hyperglycaemia, the treatment of these people is complex and should consider all vascular risk factors individually. In order to emphasize this more clearly, the previous therapy algorithm was extended to address essential cardiovascular risks in more detail (see also the separate section on lipid metabolism disorders in these practical recommendations). Arterial hypertension is also an important cardiovascular and renal risk factor. Detailed information on the treatment of hypertension was provided in the National Treatment Guideline (Nationale Versorgungsleitlinie NVL) on renal disease in diabetes in adulthood [22].

\section{Arguments for therapy stage 2}

The basic therapy plays an important role in every further step of the therapy. If people with diabetes are not able to implement these lifestyle modification measures in full or in part, even in the foreseeable future within a maximum of three months, pharmacotherapy is indicated to achieve the individual therapeutic goal. When ever possible metformin is first choice, which should be started and increased slowly by increments of $500 \mathrm{mg}$ (e. g. starting with $500 \mathrm{mg}$ at the main meal and increasing by $500 \mathrm{mg}$ per week up to a total dose of $2 \times 1000 \mathrm{mg}$ per day).

In the case of contraindications (eGFR!) or poor tolerance of Metformin (mainly dose-dependent gastrointestinal complaints), other options for monotherapy are available, the use of which should be based on patient-relevant benefit (influence on body weight, hypoglycaemia risk, metabolic effects, side effect profile and clinical endpoints). Patient preferences should also be taken into account.

In people with type 2 diabetes with HbA1c values clearly outside the individual target range (e.g. $>1.5 \%$ above the target range) at diagnosis, initial pharmacotherapy is justified, potentially also using combination therapy. After HbA1c target value is achieved, the therapy should be adjusted at individually set intervals.

\section{Arguments for therapy stage 3}

A dual combination is necessary for many patients for metabolic reasons and is more favourable with regard to side effects of individual substances, since doses can sometimes be lower when dosed in combination with other substances.

In patients with pre-existing cardiovascular or renal diseases or with a very high cardiovascular risk, substances should mostly be used in combination with metformin (eGFR > $30 \mathrm{ml} / \mathrm{min}$ !) primar- 
ily to reduce evidence-based cardiovascular and renal diseases and mortality (SGLT-2 inhibitors, GLP-1 receptor agonists).

Early combination therapy should be aimed for keeping metabolic parameters close to the agreed target range [149]. A review of the target values should take place at approximately 3-month intervals. A large number of publications providing good evidence are now available for the selection of combinations. Patient preferences, individual therapeutic goals, simplicity of treatment, existing cardiovascular diseases, possible contraindications and the considerations mentioned in stage 2 also play an important role. If the number of oral drugs becomes too high due to the complexity of the therapy, the vascular risk factors or comorbidities (e. $g$. COPD, depression, chronic pain, etc.), fixed combinations should be used wherever possible. Parenteral blood glucose-lowering principles can also be useful and helpful for these patients and significantly increase therapy adherence. The higher the HbA1c, the more likely the use of insulin, but this does not mean that the initial insulin therapy must be continued after metabolic recompensation.

The administration of more than 2 oral antidiabetic drugs may be valuable in some cases if the therapy with a GLP-1-RA or insulin is not yet indicated ( $\triangleright$ Fig. 4 ), if the patient is not yet ready for an injection therapy or if this therapy needs to be postponed for another reason.

A triple oral therapy as a combination of metformin, a DPP-4 inhibitor and an SGLT-2 inhibitor is a safe, effective and simple therapy. A potentiation of side effects was not observed under oral triple combination; they essentially corresponded to those that were observed with monotherapy for the respective substance.

A detailed medication plan and its analysis is very helpful.

If a therapy shows no effectiveness, the patient must always be consulted about therapy adherence before increasing the dosage or otherwise changing the treatment.

\section{Arguments for therapy stage 4}

Due to a lower risk for hypoglycemia and a more favorable body weight (in comparison with an intensified insulin treatment) in most patients it is recommended to start with a long-acting insulin mostly in combination with an OAD (socalled basal insulin supported oral therapy (BOT). A good alternative is to support an OAD therapy with a GLP-1-RA therapy.

Insulin dose reduction should be considered when kidney function deteriorates in order to avoid severe hypoglycaemia.

A combination of GLP-1-RA with oral antidiabetic drugs (except DPP-4 inhibitors) is an effective treatment if the individual therapeutic goal has not been achieved with the existing oral antidiabetic drugs in mono- or combination therapy or if side effects make a new therapeutic strategy necessary. In principle, the use of GLP1-RA should be considered before starting insulin therapy, especially due to the very low hypoglycaemia risk of the substance class and the advantageous cardiovascular and renal outcome data of some of these substances (which should then be preferred).

Combining a GLP-1-RA with a basal insulin results in a significant delay in the intensification of antidiabetic therapy (e. g. escalation of the basal insulin dose or additional administration of prandial insulin), in significantly better metabolic control without a significant increase in the risk of hypoglycaemia and in favourable weight effects [150-154].
Only when these combination therapies are no longer sufficiently effective or indicated, the next step is to further intensify insulin therapy with prandial insulin.

Flexibility in therapy decisions based on the heterogeneity of type 2 diabetes and individual therapy goals is necessary at every stage of treatment. In most cases, it takes time, empathy and comprehension to convince the patient to accept injection treatment and a detailed patient training is necessary. In individual cases, CSII is indicated if the therapeutic goal is not achieved adequately using ICT.

\section{Therapy of dyslipidaemia}

Here we refer to:

- ESC/EAS Guidelines for the Management of Dyslipidemia [155]

- DDG position paper on lipid therapy in patients with diabetes [156]

- Position paper on lipid therapy in patients with diabetes mellitus in these practical recommendations [Diabetologie und Stoffwechsel 2019; 14 (Suppl 2): S226-S231]

\section{Therapy of arterial hypertension}

Here we refer to:

- 2018-ESC/ESH Guidelines for the Management of Arterial Hypertension [9]

- NVL kidney disease in adult diabetes [22]

German Diabetes Association: Clinical Practice Guidelines

This is a translation of the DDG clinical practice guideline published in Diabetologie 2019; 14 (Suppl 2): S111-S118.

\section{Conflict of Interest}

R. Landgraf is the lead author and declares the following potential conflicts of interest: Advisory Boards: Lilly Deutschland, Novo Nordisk Pharma; has received lecture fees from: AstraZeneca, Berlin Chemie, Lilly Deutschland, Novo Nordisk Pharma. Other activities: Representative of the Executive Board of the German Diabetes Foundation, Steering committee for the development and updating of the National Treatment Guidelines/Nationalen Versorgungsleitlinien Diabetes.

J. Aberle is a member of advisory boards and has received lecture fees from: Astra Zeneca, Berlin-Chemie, Boehringer-Ingelheim, Eli Lilly \& Co, Novo Nordisk, Roche Diabetes Care. Institutional research funding: Astra Zeneca.

A. L. Birkenfeld is member of Advisory Boards and has received lecture fees from: Amgen, Astra Zeneca, Boehringer-Ingelheim, Eli Lilly \& Co, Merck Sharp \& Dohme, Novo Nordisk, Sanofi. Institutional research funding: Boehringer Ingelheim.

B. Gallwitz declares the following potential conflicts of interest over the last 3 years: Advisory Boards/Consultancy: Amgen, AstraZeneca, Bayer Vital, Boehringer Ingelheim, Eli Lilly \& Co., Merck Sharp \& Dohme, Mylan, Novo Nordisk; Lecturing activities: Amgen, AstraZeneca, Bristol Myers Squibb, Boehringer-Ingelheim, Eli Lilly \& Co., Merck Sharp \& Dohme, Novartis, Novo Nordisk, Sanofi; Company shares: none.

M. Kellerer is a co-author and declares the following potential conflicts of interest: Research support: GlaxoSmithKline, AstraZeneca; Consultancy: Abbott, AstraZeneca, Boehringer Ingelheim, Lilly, MSD, Novo 
Nordisk; Lecturing activities: AstraZeneca, Boehringer Ingelheim, Lilly, MSD, Novo Nordisk, Novartis, Janssen-Cilag, Sanofi.

$\mathrm{H}$. Klein declares the following potential conflicts of interest: Advisory Board: AstraZeneca, Janssen Cilag, Boehringer Ingelheim; Lecture fees: Berlin-Chemie.

D. Müller-Wieland declares the following potential conflicts of interest: Member of the Advisory Board and lecture fees in the last 3 years from the following companies: Amgen, MSD, AstraZeneca, Novartis, Boehringer Ingelheim, Lilly, Novo Nordisk, Roche Diabetes Care, Sanofi.

M. A. Nauck declares the following potential conflicts of interest: Member of the Advisory Board: Berlin Chemie, Boehringer Ingelheim, Fractyl, Eli Lilly \& Co., GlaxoSmithKline, MSD, Novo Nordisk, Intarcia Therapeutics; Consultancy fees: AstraZeneca, Berlin Chemie, Boehringer Ingelheim, Eli Lilly \& Co., GlaxoSmithKline, Intarcia Therapeutics, MSD, Novo Nordisk; Fees: AstraZeneca, Berlin Chemie, Boehringer Ingelheim, Eli Lilly \& Co., Medscape, MSD, Novo Nordisk, Research Support: AstraZeneca, Eli Lilly \& Co., GSK, MSD, Novo Nordisk, Novartis.

H.-M. Reuter declares that he has served on Advisory Boards for Lilly Germany, Berlin-Chemie, MSD, Novo Nordisk, BMS and AstraZeneca over the past 3 years and has received lecture fees from Lilly, MSD, Berlin-Chemie, BMS, Amgen, Bayer, Boehringer Ingelheim, Sanofi and AstraZeneca.

E. Siegel declares that he had no economic or personal conflicts of interest concerning this manuscript.

\section{References}

[1] Nationale Versorgungsleitlinien www.versorgungsleitlinien.de

[2] KGMM Alberti, Eckel RH, Grundy SM et al. Harmonizing the metabolic syndrome. Circulation 2009; 120: 1640-1645

[3] Heinemann L, Kaiser P, Freckmann G et al. HbA1c-Messung in Deutschland: Ist die Qualität ausreichend für Verlaufskontrolle und Diagnose? Diabetologie 2018; 13: 46-53

[4] Petersmann A, Müller-Wieland D, Müller UA et al. Definition, Klassifikation und Diagnostik des Diabetes mellitus. Diabetolgie 2019; 14: (Suppl 2): S111-S117

[5] Landgraf R, Nauck M, Freckmann G et al. Fallstricke bei der Diabetesdiagnostik: Wird zu lax mit Laborwerten umgegangen? Dtsch Med Wochenschr 2018; 143: 1549-1555

[6] Nationale VersorgungsLeitlinie (NVL) Diabetes - Strukturierte Schulungsprogramme. 2018; www.leitlinien.de/nvl/diabetes/ schulungsprogramme

[7] Wang R, Song Y, Yan Y et al. Elevated serum uric acid and risk of cardiovascular or all-cause mortality in people with suspected or definite coronary artery disease: A meta-analysis. Atherosclerosis 2016; 254: 193-199

[8] Praxisempfehlungen DDG zu Lipidtherapie. Diabetologie. 2019;

[9] The Task Force for the management of arterial hypertension of the European Society of cardiology (ESC) and the European Society of Hypertension (ESH) 2018 ESC/ESH Guidelines for the management of arterial hypertension. Eur Heart J 2018; 39: 3021-3104

[10] Forouhi NG, Misra A, Mohan V et al. Dietary and nutritional approaches for prevention and management of type 2 diabetes. BM] 2018; 361: k2234

[11] Serra-Majem L, Román-Viñas B, Sanchez-Villegas A et al. Benefits of the Mediterranean diet: Epidemiological and molecular aspects. Mol Aspects Med 2019; 67: 1-55

[12] Taylor R, Al-Mrabeh A, Sattar N. Understanding the mechanisms of reversal of type 2 diabetes. Lancet Diabetes Endocrinol 2019; doi:S2213- 8587 30076-2
[13] Evert AB, Dennison M, Gardner CD et al. Nutrition therapy for adults with diabetes or prediabetes: A consensus report. Diabetes Care 2019; 42: 731-754

[14] Kempf K, Altpeter B, Berger J et al. Efficacy of the telemedical lifestyle intervention program TeLiPro in advanced stages of type 2 diabetes: A randomized controlled trial. Diabetes Care 2017; 40: 863-871

[15] Lean ME], Leslie WS, Barnes AC et al. Primary care-led weight management for remission of type 2 diabetes (DiRECT): An open-label, cluster- randomised trial. Lancet 2018; 391: 541-551

[16] Adipositas - Prävention und Therapie AWMF Register Nr 050-001

[17] Lawall H, Huppert P, Rümenapf $G$ et al. Periphere arterielle Verschluss krankheit (PAVK), Diagnostik, Therapie und Nachsorge. AWMF Register Nr 065-003 2015

[18] Nationale VersorgungsLeitlinie Neuropathie bei Diabetes im Erwachse- nenalter. 2016; www.leitlinien.de/mdb/downloads/nvl/ diabetes- mellitus/dm-neuropathie

[19] Nationale VersorgungsLeitlinie Prävention und Therapie von Netzhautkomplikationen bei Diabetes. 2016; www.leitlinien.de/nvl/html/ netz.hautkomplikationen

[20] Nationale VersorgungsLeitlinie (NVL) Typ-2-Diabetes Präventionsund Behandlungsstrategien für Fußkomplikationen. 2018; www. leitlinien.de/nvl/diabetes/fusskomplikationen

[21] Roeb E, Steffen HM, Bantel H et al. S2k Leitlinie: Nicht-alkoholische Fettlebererkrankungen. AWMF Register Nr 021-025 2015

[22] Nationale VersorgungsLeitlinie Nierenerkrankungen bei Diabetes im Erwachsenenalter 2018; www.leitlinien.de/nvl/diabetes/nierenerkrankungen

[23] Nationale VersorgungsLeitlinie Chronische Herzinsuffizienz. 2018; https://www.leitlinien.de/nvl/html/nvl-chronische-herzinsuffizienz

[24] Nationale Versorgungs-Leitlinie Chronische Koronare Herzerkrankung (KHK). 2016; https://www.leitlinien.de/mdb/downloads/nvl/khk/, www.leitlinien.de/nvl/html/nvl-chronische-khk

[25] Piercy KL, Richard P, Troiano RP et al. The physical activity guidelines for Americans. JAMA 2018; 320: 2020-2028

[26] The Look AHEAD Research Group Cardiovascular effects of intensive lifestyle intervention in type 2 diabetes. N Engl J Med 2013; 369: $145-154$

[27] Unick JL, Gaussoin SA, Hill JO et al. Objectively assessed physical activity and weight loss maintenance among individuals enrolled in a lifestyle intervention. Obesity (Silver Spring) 2017; 25: 1903-1909

[28] The Look AHEAD Research Group Association of the magnitude of weight loss and changes in physical fitness with long-term cardiovascular disease outcomes in overweight or obese people with type 2 diabetes: A post-hoc analysis of the Look AHEAD randomized clinical trial. Lancet Diabetes Endocrinol 2016; 4: 913-921

[29] Gregg EW, Lin ], Bardenheier B et al. Impact of intensive lifestyle inter vention on disability-free life expectancy: The LookAHEAD Study. Diabetes Care 2018; 41: 1040-1048

[30] Yang D, Yang Y, Li Y et al. Physical exercise as therapy for type 2 diabetes mellitus: From mechanism to orientation. Ann Nutr Metab 2019; 74: 313-321

[31] Tarp ], Støle AP, Blond K et al. Cardiorespiratory fitness, muscular strength and risk of type 2 diabetes: A systematic review and metaanalysis. Diabetologia 2019; 62: 1129-1142

[32] Liu Y, Ye W, Chen Q et al. Resistance exercise intensity is correlated with attenuation of $\mathrm{HbA} 1 \mathrm{c}$ and insulin in patients with type 2 diabetes: A systematic review and meta-analysis. Int J Environ Res Public Health 2019; 16: E140

[33] Pan A, Yeli Wang Y, Talaei $M$ et al. Relation of active, passive, and quit ting smoking with incident diabetes: A meta-analysis and systematic review. Lancet Diabetes Endocrinol 2015; 3: 958-996 
[34] www.bfarm.de/SharedDocs/Risikoinformationen/Pharmakovigilanz/ DE/RV_STP/m-r/metformin.html

[35] Lazarus B, Wu A, Shin Jl et al. Association of metformin use with risk of lactic acidosis across the range of kidney function. A communitybased cohort tudy. JAMA Intern Med 2018; 178: 903-910

[36] Griffin SJ, Leaver JK, Irving G] et al. Impact of metformin on cardiovascu- lar disease: A meta-analysis of randomised trails among people with type 2 diabetes. Diabetologia 2017; 60: 1620-1629

[37] Palmer SC, Mavridis D, Nicolucci A et al. Comparison of clinical outcomes and adverse events associated with glucose-lowering drugs in patients with type 2 diabetes. A meta-analysis. JAMA 2016; 316: 313-324

[38] Madsen KS, Kähler P, Kähler LKA et al. Metformin and second- or third- generation sulphonylurea combination therapy for adults with type 2 diabetes mellitus. Cochrane Database Syst Rev 2019; 4 CD012368

[39] Mallik R, Chowdhury TA. Metformin in cancer. Diabetes Res Clin Pract 2018; 143: 409-419

[40] Thakur S, Daley B, Klubo-Gwiezdzinska J. The role of the antidiabetic drug metformin in the treatment of endocrine tumors. J Mol Endocrinol 2019, doi:JME-19-0083.R1

[41] De A, Kuppusamy G. Metformin in breast cancer: Preclinical and clinical evidence. Curr Probl Cancer 2019, doi:S0147-0272(19)30047-9

[42] Rahmani J, Manzari N, Thompson J et al. The effect of metformin on biomarkers associated with breast cancer outcomes: A systematic review, meta-analysis, and dose-response of randomized clinical trials. Clin Transl Oncol 2019, doi:10.1007/s12094-019-02108-9

[43] Fong W.To KKW Drug repurposing to overcome resistance to various therapies for colorectal cancer. Cell Mol Life Sci 2019, doi:10.1007/ s00018-019-03134-0

[44] Feng Z, Zhou X, Liu N et al. Metformin use and prostate cancer risk: A meta-analysis of cohort studies. Medicine (Baltimore) 2019; 98 : e14955

[45] Marx N, Rosenstock J, Kahn SE et al. Design and baseline characteristics of the CARdiovascular Outcome Trial of LINAgliptin Versus Glimepiride in Type 2 Diabetes (CAROLINA $®$ ). Diab Vasc Dis Res 2015; 12: 164-174

[46] Rosenstock J, Kahn SE, Johansen OE et al. for the CAROLINA Investigators. Effect of Linagliptin vs Glimepiride on Major Adverse Cardiovascular Outcomes in Patients With Type 2 Diabetes: The CAROLINA Randomized Clinical Trial. JAMA 2019 Sep 19. doi: 10.1001/jama.2019.13772

[47] Rados DV, Pinto LC, Remonti LR et al. The association between sulfony lurea use and all-cause and cardiovascular mortality: A meta-analysis with trial sequential analysis of randomized clinical trials. PLoS Med 2016; 13: e1002091

[48] Azoulay L, Suissa S. Sulfonylureas and the risks of cardiovascular events and death: A methodological meta-regression analysis of the observa tional studies. Diabetes Care 2017; 40: 706-714

[49] Bain S, Druyts E, Balijepalli C et al. Cardiovascular events and all-cause mortality associated with sulphonylureas compared with other antihyperglycaemic drugs: A Bayesian meta-analysis of survival data. Diabetes Obes Metab 2017; 19: 329-335

[50] Zhuang XD, He X, Yang DY et al. Comparative cardiovascular outcomes in the era of novel anti-diabetic agents: A comprehensive network meta-analysis of 166371 participants from 170 randomized controlled trials. Cardiovasc Diabetol 2018; 17: 79

[51] Powell WR, Christiansen CL, Miller DR. Meta-analysis of sulfonylurea therapy on long-term risk of mortality and cardiovascular events compared to other oral glucose-lowering treatments. Diabetes Ther 2018; 9: 1431-1440
[52] Simpson SH, Lee ], Choi S et al. Mortality risk among sulfonylureas: An-systematic review and network meta-analysis. Lancet Diabetes Endocri- nol 2015; 3: 43-5134

[53] Hemmingsen B, Schroll JB, Lund SS et al. Sulphonylurea monotherapy for patients with type 2 diabetes mellitus. Cochrane Database Syst Rev 2013; 4: CD009008

[54] Hemmingsen B, Schroll JB, Jorn Wetterslev J et al. Sulfonylurea vs. metformin monotherapy in patients with type 2 diabetes: $\mathrm{A}$ Cochrane systematic review and meta-analysis of randomized clinical trials and trial sequential analysis. CMAJ Open 2014; 2: E162-E175

[55] Chen K, Kang D, Yu M et al. Direct head-to-head comparison of glycae- mic durability of dipeptidyl peptidase- 4 inhibitors and sulphonylureas in patients with type 2 diabetes mellitus: A meta-analysis of long-term randomized controlled trials. Diabetes Obes Metab 2018; 20: 1029-1033

[56] Scirica BM, Bhatt DL, Braunwald E et al. Saxagliptin and cardiovascular outcomes in patients with type 2 diabetes mellitus. N Engl J Med 2013; 369: 1317-1326

[57] White WB, Cannon CP, Heller SR EXAMINE Investigators et al. Alogliptin after acute coronary syndrome in patients with type 2 diabetes. N Engl J Med 2013; 369: 1327-1335

[58] Green JB, Bethel MA, Armstrong PW et al. TECOS Study Group. N Engl J Med 2015; 373: 232-242

[59] Rosenstock J, Perkovic V, Johansen OE CARMELINA Investigators et al. Effect of linagliptin vs. placebo on major cardiovascular events in adults with type 2 diabetes and high cardiovascular and renal risk: The CARMELINA Randomized Clinical Trial. JAMA 2019; 321: 69-79

[60] Monami M, Ahrén B, Dicembrini I et al. Dipeptidyl peptidase-4 inhibitors and cardiovascular risk: A meta-analysis of randomized clinical trials. Diabetes Obes Metab 2013; 15: 112-120

[61] Xu S, Zhang X, Tang L et al. Cardiovascular effects of dipeptidylpeptidase-4 inhibitor in diabetic patients with and without established cardio- vascular disease: A meta-analysis and systematic review. Postgrad Med 2017; 129: 205-215

[62] Zheng SL, Roddick A], Aghar-Jaffar R et al. Association between use of sodium-glucose cotransporter 2 inhibitors, glucagon-like peptide 1 agonists, and dipeptidyl peptidase 4 inhibitors with all-cause mortality in patients with type 2 diabetes. A systematic review and meta-analysis. JAMA 2018; 319: 1580-1591

[63] Ling J, Cheng P, Ge L et al. The efficacy and safety of dipeptidyl peptidase- 4 inhibitors for type 2 diabetes: A Bayesian network meta-analysis of 58 randomized controlled trials. Acta Diabetologica 2019; 56: 249-272

[64] Li L, Li S, Deng K et al. Dipeptidyl peptidase-4 inhibitors and risk of heart failure in type 2 diabetes: Systematic review and meta-analysis of randomized and observational studies. BMJ 2016; 352: i610

[65] Guo WQ, Li L, Su Q et al. Effect of dipeptidylpeptidase-4 inhibitors on heart failure: A network meta-analysis. Value Health 2017; 20: $1427-1430$

[66] Nauck MA, Meier J], Cavender MA et al. Cardiovascular actions and clinical outcomes with glucagon-like peptide- 1 receptor agonists and dipeptidyl peptidase-4 inhibitors. circulation 2017; 136: 849-870

[67] Tkáč I, Raz I. Combined analysis of three large interventional trials with gliptins indicates increased incidence of acute pancreatitis in patients with type 2 diabetes. Diabetes Care 2017; 40: 284-286

[68] Abrahami D, Douros A, Yin H et al. Dipeptidyl peptidase-4 inhibitors and incidence of inflammatory bowel disease among patients with type 2 diabetes: Population based cohort study. BMJ 2018; 360: k872

[69] Li G, Crowley M], Tang H et al. Dipeptidyl peptidase 4 inhibitors and risk of inflammatory bowel disease among patients with type 2 diabetes: A meta-analysis of randomized controlled trials. Diabetes Care 2019; 42: e119-e121 
[70] Storgaard H, Gluud LL, Bennett C et al. Benefits and harms of sodium- glucose co-transporter 2 inhibitors in patients with type 2 diabetes: A systematic review and meta-analysis. PLoS One 2016; 11 : e0166125

[71] Monami M, Liistro F, Scatena A et al. Short and medium-term efficacy of sodium glucose co-transporter-2 (SGLT-2) inhibitors: A metaanalysis of randomized clinical trials. Diabetes Obes Metab 2018; 20: 1213-1222

[72] Usman MS, Siddiqi T], Memon MM et al. Sodium-glucose co-transporter 2 inhibitors and cardiovascular outcomes: A systematic review and meta-analysis. Eur J Prev Cardiol 2018; 25: 495-502

[73] Mishriky BM, Tanenberg RJ, Sewell KA et al. Comparing SGLT-2 inhibitors to DPP-4 inhibitors as an add-on therapy to metformin in patients with type 2 diabetes: A systematic review and meta-analysis. Diabetes Metab 2018; 44: 112-120

[74] Seidu S, Kunutsor SK, Cos X on behalf of primary care diabetes Europe et al. SGLT2 inhibitors and renal outcomes in type 2 diabetes with or without renal impairment: A systematic review and meta-analysis. Prim Care. Diabetes 2018; 12: 265-283

[75] Rådholm K, Wu JH, Wong MG et al. Effects of sodium-glucose cotrans-porter-2 inhibitors on cardiovascular disease, death and safety outcomes in type 2 diabetes - A systematic review. Diabetes Res Clin Pract 2018; 140: 118-128

[76] Sinha B, Ghosal S. Meta-analyses of the effects of DPP-4 inhibitors, SGLT2 inhibitors and GLP1 receptor analogues on cardiovascular death, myocardial infarction, stroke and hospitalization for heart failure. Diabetes Res Clin Pract 2019; 150: 8-16

[77] Zheng SL, Roddick A], Aghar-Jaffar R et al. Association between use of sodium-glucose cotransporter 2 inhibitors, glucagon-like peptide 1 agonists, and dipeptidyl peptidase 4 inhibitors with all-cause mortality in patients with type 2 diabetes: A systematic review and Meta-analysis. JAMA 2018; 319: 1580-1591

[78] Puckrin R, Saltiel MP, Reynier P et al. SGLT-2 inhibitors and the risk of infections: A systematic review and meta-analysis of randomized con trolled trials. Acta Diabetol 2018; 55: 503-514

[79] Lega IC, Bronskill SE, Campitelli MA et al. Sodium glucose cotransporter 2 inhibitors and risk of genital mycotic and urinary tract infection: A population-based study of older women and men with diabetes. Diabetes Obes Metab 2019, doi:10.1111/dom.13820. [Epub ahead of print]

[80] Aronson R, Frias ], Goldman A et al. Long-term efficacy and safety of ertugliflozin monotherapy in patients with inadequately controlled T2DM despite diet and exercise: VERTIS MONO extension study. Diabetes Obes Metab 2018; 20: 1453-1460

[81] Pratley RE, Eldor R, Raji A et al. Ertugliflozin plus sitagliptin vs. either individual agent over 52 weeks in patients with type 2 diabetes mellitus inadequately controlled with metformin: The VERTIS FACTORIAL randomized trial. Diabetes Obes Metab 2018; 20: $1111-1120$

[82] Fralick M, Schneeweiss S, Patorno E. Risk of diabetic ketoacidosis after initiation of an SGLT2 inhibitor. N Engl J Med 2017; 376 : 2300-2303

[83] Monami M, Nreu B, Zannoni S et al. Effects of SGLT2 inhibitors on diabetic ketoacidosis: A meta-analysis of randomised controlled trials. Diabetes Res Clin Pract 2017; 130: 53-60

[84] Fadini GP, Bonora BM, Avogaro A. SGLT2 inhibitors and diabetic ketoacidosis: Data from the FDA Adverse Event Reporting System. Diabetologia 2017; 60: 1385-1389

[85] Donnan K, Segar L. SGLT2 inhibitors and metformin: Dual antihyperglycemic therapy and the risk of metabolic acidosis in type 2 diabetes. Eur J Pharmacol 2019; 846: 23-29
[86] Zinman B, Wanner C, Lachin JM et al. Empagliflozin, cardiovascular outcomes, and mortality in type 2 diabetes. N Engl J Med 2015; 373: 2117-2128

[87] Wanner C, Inzucchi SE, Zinman B. Empagliflozin and progression of kidney disease in type 2 diabetes. $N$ Engl J Med 2016; 375: 323-334

[88] Cherney DZI, Zinman B, Inzucchi SE et al. Effects of empagliflozin on the urinary albumin-to-creatinine ratio in patients with type 2 diabetes and established cardiovascular disease: An exploratory analysis from the EMPA-REG OUTCOME randomised, placebo-controlled trial. Lancet Diabetes Endocrinol 2017; 5: 610-621

[89] Sattar N, McLaren J, Kristensen SL et al. SGLT2 Inhibition and cardiovascular events: Why did EMPA-REG Outcomes surprise and what were the likely mechanisms? Diabetologia 2016; 59: 13331339

[90] Ferrannini E, Mark M, Mayoux E et al. CV Protection in the EMPA-REG OUTCOME Trial: A "Thrifty Substrate" Hypothesis. Diabetes Care 2016; 39: 1108-1114

[91] https://www.gba.de/downloads/40-268-4342/2017-04-20_DMPARL_Aenderung-Anlage-1_DMP-Diabetes-mellitus_TrG.pdf

[92] Neal B, Perkovic V, Mahaffey KW et al. CANVAS Program Collaborative Group canagliflozin and cardiovascular and renal events in type 2 diabetes. N Engl J Med 2017; 377: 644-657

[93] Perkovic V, Jardine M], Neal N et al. Canagliflozin and renal outcomes in type 2 diabetes and nephropathy. $\mathrm{N}$ Engl J Med 2019; 380: 2295-2306

[94] Wiviott SD, Raz I, Bonaca MP. DECLARE-TIMI 58 Investigators et al. Dapagliflozin and cardiovascular outcomes in type 2 diabetes. $\mathrm{N}$ Engl J Med 2019; 380: 347-357

[95] Mosenzon O, Wiviott SD, Cahn A et al. Effects of dapagliflozin on development and progression of kidney disease in patients with type 2 diabetes: An analysis from the DECLARE-TIMI 58 randomised trial. Lancet Diabetes Endocrinol 2019; 7: 606-617

[96] Furtado RHM, Bonaca MP, Raz I. Dapagliflozin and cardiovascular out- comes in patients with type 2 diabetes mellitus and previous myocardial infarction. Circulation 2019; 139: 2516-2527

[97] Kato ET, Silverman MG, Mosenzon O et al. Effect of dapagliflozin on heart failure and mortality in type 2 diabetes mellitus. Circulation 2019; 139: 2528-2536

[98] www.ema.europa.eu/ema/index.jsp?curl = pages/medicines/human/ referrals/SGLT2_inhibitors_(previously_Canagliflozin)/human_referral_ prac_000059.jsp\&mid = WC0b01ac05805c5

[99] Scheen AJ. Does lower limb amputation concern all SGLT2 inhibitors? Nat Rev Endocrinol 2018; 14: 326-328

[100] Fioretto P, Del Prato S, Buse JB et al. Efficacy and safety of dapagliflozin in patients with type 2 diabetes and moderate renal impairment (CKD Stage 3A): The DERIVE Study. Diabetes Obes Metab 2018, doi:10.1111/dom. 13413

[101] Inzucchi SE, lliev H, Pfarr E et al. Empagliflozin and assessment of lower limb amputations in the EMPA-REG OUTCOME trial. Diabetes Care 2018; 41: e4-e5

[102] Zhou Z, Jardine M, Perkovic V et al. Canagliflozin and fracture risk in individuals with type 2 diabetes: Results from the CANVAS Program. Diabetologia 2019; published online Aug 11:

[103] Kohler S, Kaspers S, Salsali A et al. Analysis of fractures in patients with type 2 diabetes treated with empagliflozin in pooled data from placebo- controlled trials and a head-to-head study versus glimepiride. Diabetes Care 2018; 41: 1809-1816

[104] Ruanpeng D, Ungprasert P, Sangtian J et al. Sodium-glucose cotrans- porter 2 (SGLT2) inhibitors and fracture risk in patients with type 2 diabetes mellitus: A meta-analysis. Diabetes Metab Res Rev 2017, doi:10.1002/dmrr.2903 
[105] Tang HL, Li DD, Zhang J] et al. Lack of evidence for a harmful effect of sodium-glucose co-transporter 2 (SGLT2) inhibitors on fracture risk among type 2 diabetes patients: a network and cumulative meta-analysis of randomized controlled trials. Diabetes Obes Metab 2016; 18: 1199-1206

[106] Levin PA, Nguyen H, Wittbrodt ET et al. Glucagon-like peptide-1 receptor agonists: A systematic review of comparative effectiveness research. Diabetes Metab Syndr Obes 2017; 10: 123-139

[107] Marso SP, Daniels GH, Brown-Frandsen K et al. Liraglutide and cardiovascular outcomes in type 2 diabetes. N Engl J Med 2016; 375: 311-322

[108] Verma S, Bhatt DL, Bain SC et al. Effect of liraglutide on cardiovascular events in patients with type 2 diabetes mellitus and polyvascular disease. Circulation 2018; 137: 2179-2183

[109] Marso SP, Nauck MA, Monk Fries T et al. Myocardial infarction subtypes in patients with type 2 diabetes mellitus and the effect of liraglutide therapy (from the LEADER Trial). Am J Cardiol 2018; 121: 1467-1470

[110] Mann JFE, Ørsted DD, Buse JB. Liraglutide and renal outcomes in type 2 diabetes. N Engl J Med 2017; 377: 839-848

[111] Kristensen SL, Rørth R, Jhund PS. Cardiovascular, mortality, and kidney outcomes with GLP-1 receptor agonists in patients with type 2 diabetes: A systematic review and meta-analysis of cardiovascular outcome trials. Lancet Diabetes Endocrinol 2019; published Online August 14

[112] Liu J, Li L, Deng K et al. Incretin based treatments and mortality in patients with type 2 diabetes: Systematic review and meta-analysis. BM] 2017; 357: j2499

[113] Gerstein HC, Colhoun HM, Dagenais GR for the REWIND Investigators et al. Dulaglutide and cardiovascular outcomes in type 2 diabetes (REWIND): A double-blind, randomised placebo-controlled trial. Lancet 2019; 394: 121-130

[114] Gerstein HC, Colhoun HM, Dagenais GR. for the REWIND Investigators et al. Dulaglutide and renal outcomes in type 2 diabetes: An exploratory analysis of the REWIND randomised, placebo-controlled trial. Lancet 2019; 394: 131-138

[115] Home PD, Ahrén B, Reusch JEB et al. Three-year data from 5 HARMONY phase 3 clinical trials of albiglutide in type 2 diabetes mellitus: Long- term efficacy with or without rescue therapy. Diabetes Res Clin Pract 2017; 131: 49-60

[116] Ahrén B, Carr MC, Murphy K et al. Albiglutide for the treatment of type 2 diabetes mellitus: An integrated safety analysis of the HARMONY phase 3 trials. Diabetes Res Clin Pract 2017; 126: 230-239

[117] Hernandez AF, Green JB, Janmohamed S et al. Harmony Outcomes committees and investigators. Albiglutide and cardiovascular outcomes in patients with type 2 diabetes and cardiovascular disease (Harmony Outcomes): A double-blind, randomised placebo-controlled trial. Lancet 2018; 392: 1519-1529

[118] Holman RR, Bethel MA, Mentz RJ et al. Effects of once-weekly exenatide on cardiovascular outcomes in type 2 diabetes. $\mathrm{N}$ Engl J Med 2017; 377: 1228-1239

[119] Bethel MA, Patel RA, Merrill P et al. Cardiovascular outcomes with glucagon-like peptide- 1 receptor agonists in patients with type 2 diabetes: A meta analysis. Lancet Diabetes Endocrinol 2018; 6: 105-113

[120] Marso SP, Bain SC, Consoli A et al. Semaglutide and cardiovascular outcomes in patients with type 2 diabetes. N Engl J Med 2016; 375 : 1834-1844

[121] Leiter LA, Bain SC, Hramiak I et al. Cardiovascular risk reduction with once-weekly semaglutide in subjects with type 2 diabetes: A post hoc analysis of gender, age, and baseline CV risk profile in the SUSTAIN 6 trial. Cardiovasc Diabetol 2019; 18: 73
[122] Husain M, Birkenfeld AL, Donsmark M. PIONEER 6 Investigators et al. Oral semaglutide and cardiovascular outcomes in patients with type 2 diabetes. N Engl J Med 2019, doi:10.1056

[123] Zheng SL, Roddick AJ, Aghar-Jaffar R et al. Association between use of sodium-glucose cotransporter 2 inhibitors, glucagon-like peptide 1 agonists, and dipeptidyl peptidase 4 inhibitors with all-cause mortality in patients with type 2 diabetes. A systematic review and metaanalysis. JAMA 2018; 319: 1580-1591

[124] Dicembrini I, Nreu B, Scatena A et al. Microvascular effects of glucagon-like peptide- 1 receptor agonists in type 2 diabetes: A metaanalysis of randomized controlled trials. Acta Diabetol 2017; 54: 933-941

[125] Vilsbø॥ T, Bain SC, Leiter LA et al. Semaglutide, reduction in glycated haemoglobin and the risk of diabetic retinopathy. Diabetes Obes Metab 2018; 20: 889-897

[126] Monami M, Nreu B, Scatena A et al. Safety issues with glucagon-like peptide- 1 receptor agonists (pancreatitis, pancreatic cancer and cholelithiasis): Data from randomized controlled trials. Diabetes Obes Metab 2017; 19: 1233-1241

[127] Nauck MA, Meier J], Schmidt WE. Incretin-based glucose-lowering medications and the risk of acute pancreatitis and/or pancreatic cancer: Reassuring data from cardio-vascular outcome trials. Diabetes Obes Metab 2017; 19: 1327-1328

[128] Azoulay L, Filion KB, Platt RW et al. Association between incretinbased drugs and the risk of acute pancreatitis. JAMA Intern Med 2016; 176: 1464-1473

[129] Wang T, Wang F, Gou Z et al. Using real-world data to evaluate the association of incretin-based therapies with risk of acute pancreatitis: A meta-analysis of 1324515 patients from observational studies. Diabetes Obes Metabol 2015; 17: 32-41

[130] Russell-Jones D, Pouwer F, Khunti K. Identification of barriers to insulin therapy and approaches to overcoming them. Diabetes Obes Metab 2018; 20: 488-496

[131] Marso SP, McGuire DK, Zinman B DEVOTE Study Group et al. Efficacy and safety of degludec vs. glargine in type 2 diabetes. New Engl J Med 2017; 377: 723-732

[132] Pieber TR, Marso SP, McGuire DK et al. DEVOTE 3: Temporal relationships between severe hypoglycaemia, cardiovascular outcomes and- mortality. Diabetologia 2018; 61: 58-65

[133] Lau IT, Lee KF, So WY et al. Insulin glargine $300 \mathrm{U} / \mathrm{mL}$ for basal insulin therapy in type 1 and type 2 diabetes mellitus. Diabetes Metab Syndr Obes 2017; 10: 273-284

[134] Ritzel R, Roussel R, Giaccari A et al. Better glycaemic control and less hypoglycaemia with insulin glargine $300 \mathrm{U} / \mathrm{mL}$ vs. glargine $100 \mathrm{U} / \mathrm{mL}$ : 1 -year patient-level meta-analysis of the EDITION clinical studies in people with type 2 diabetes. Diabetes Obes Metab 2018; 20 : 541-548

[135] Bonadonna RC, Renard E, Cheng A et al. Switching to insulin glargine $300 \mathrm{U} / \mathrm{mL}$ : Is duration of prior basal insulin therapy important? Diabetes Res Clin Pract 2018; 142: 19-25

[136] Linnebjerg H, Lam EC, Seger ME et al. Comparison of the pharmacoki- netics and pharmacodynamics of LY2963 016 insulin glargine and EU- and US-Approved versions of lantus insulin glargine in healthy subjects: Three randomized euglycemic clamp studies. Diabetes Care 2015; 38: 2226-2233

[137] Rosenstock J, Hollander P, Bhargava A et al. Similar efficacy and safety of LY2963 016 insulin glargine and insulin glargine (Lantus $®$ ) in patients with type 2 diabetes who were insulin-naïve or previously treated with insulin glargine: A randomized, double-blind controlled trial (ELEMENT 2 study). Diabetes Obes Metabol 2015; 17: 734-741

[138] Yamada T, Kamata R, Ishinohachi K et al. Biosimilar vs. originator insulins: Systematic review and meta-analysis. Diabetes Obes Metab 2018; 20: 1787-1792 
[139] But A, De Bruin ML, Bazelier MT et al. Cancer risk among insulin users: Comparing analogues with human insulin in the CARING five-country cohort study. Diabetologia 2017; 60: 1691-1703

[140] Maiorino MI, Chiodini P, Bellastella G et al. Insulin and glucagon-like peptide 1 receptor agonist combination therapy in type 2 diabetes: A systematic review and meta-analysis of randomized controlled trials. Diabetes Care 2017; 40: 614-624

[141] Guja C, Frías JP, Somogyi A et al. Effect of exenatide QW or placebo, both added to titrated insulin glargine, in uncontrolled type 2 diabetes: The DURATION-7 randomized study. Diabetes Obes Metab 2018; 20: 1602-1161

[142] Rodbard HW, Lingvay I, Reed J et al. Semaglutide added to basal insulin in type 2 diabetes (SUSTAIN 5): A randomized, controlled trial. J Clin Endocrinol Metab 2018; 103: 2291-2301

[143] Gentile S, Fusco A, Colarusso S et al. A randomized, open-label, com- parative, crossover trial on preference, efficacy, and safety profiles of lispro insulin U-100 versus concentrated lispro insulin $\mathrm{U}-200$ in patients with type 2 diabetes mellitus: a possible contribution to greater treat- ment adherence. Expert Opin Drug Saf 2018; 17: 445-450

[144] Heise T, Hövelmann U, Brøndsted L et al. Faster-acting insulin aspart: earlier onset of appearance and greater early pharmacokinetic and pharmacodynamic effects than insulin aspart. Diabetes Obes Metabol 2015; 17: 682-688

[145] Bowering K, Case C, Harvey J et al. Faster aspart versus insulin aspart as part of a basal-bolus regimen in inadequately controlled type 2 diabetes: The onset 2 trial. Diabetes Care 2017; 40: 951-957

[146] The SPRINT Research Group A Randomized Trial of Intensive vs. Standard Blood-Pressure Control. N Engl J Med 2015; 373: 2103 2116

[147] Düsing R. Therapieziele bei der Hypertoniebehandlung. Dtsch Med Wochenschr 2017; 142: 1420-1429
[148] Banegas JR, Ruilope LM, de la Sierra A et al. Relationship between clinic and ambulatory blood-pressure measurements and mortality. N Engl ] Med 2018; 378: 1509-1520

[149] Khunti K, Gomes MB, Pocock S et al. Therapeutic inertia in the treatment of hyperglycaemia in patients with type 2 diabetes: A systematic review. Diabetes Obes Metab 2018; 20: 427-437

[150] Gough SC, Bode B, Woo V et al. Efficacy and safety of a fixed-ratio combination of insulin degludec and liraglutide (IDegLira) compared with its components given alone: results of a phase 3 , open-label, randomised, 26- week, treat-to-target trial in insulin-naive patients with type 2 diabetes. Lancet Diabet Endocrinol 2014; 2: 885-893

[151] Diamant M, Nauck MA, Shaginian R et al. glucagon-like peptide 1 receptor agonist or bolus insulin with optimized basal insulin in type 2 diabetes. Diabetes Care 2014; 37: 2763-2773

[152] Ahmann A, Rodbard HW, Rosenstock J et al. Efficacy and safety of liraglutide versus placebo added to basal insulin analogues (with or without metformin) in patients with type 2 diabetes: A randomized, placebocontrolled trial. Diabetes Obes Metab 2015; 17: 1056-1064

[153] Montvida O, Klein K, Kumar S et al. Addition of or switch to insulin therapy in people treated with glucagon-like peptide-1 receptor agonists: A real-world study in 66583 patients. Diabetes Obes Metab 2017; 19: 108-117

[154] Billings LK, Doshi A, Gouet D et al. Efficacy and safety of ideglira versus basal-bolus insulin therapy in patients with type 2 diabetes uncontrolled on metformin and basal insulin: The DUAL VII Random- ized Clinical Trial. Diabetes Care 2018; 41: 1009-1016

[155] Catapano AL, Graham I, De Backer G et al. 2016; ESC/EAS Guidelines for the management of dyslipidaemias. Eur Heart J 2016; 37 (39) 2999-3058

[156] Parhofer KG, Birkenfeld AL, Krone W et al. Positionspapier zur Lipid- therapie bei Patienten mit Diabetes mellitus. Diabetologie 2018; 13: S209-S213 